Rhode Island College

Digital Commons @ RIC

\title{
Theoretical Frames and Teaching Styles of Physical Therapy Faculty who Lead International Service-Learning Experiences
}

Jennifer G. Audette

Rhode Island College

Follow this and additional works at: https://digitalcommons.ric.edu/etd

Part of the Educational Assessment, Evaluation, and Research Commons

\section{Recommended Citation}

Audette, Jennifer G., "Theoretical Frames and Teaching Styles of Physical Therapy Faculty who Lead International Service-Learning Experiences" (2011). Master's Theses, Dissertations, Graduate Research and Major Papers Overview. 44.

https://digitalcommons.ric.edu/etd/44

This Dissertation is brought to you for free and open access by the Master's Theses, Dissertations, Graduate Research and Major Papers at Digital Commons @ RIC. It has been accepted for inclusion in Master's Theses, Dissertations, Graduate Research and Major Papers Overview by an authorized administrator of Digital Commons @ RIC. For more information, please contact digitalcommons@ric.edu. 


\section{Theoretical Frames and Teaching Styles of Physical Therapy Faculty Who Lead International Service-Learning Experiences}

Jennifer Gail Audette

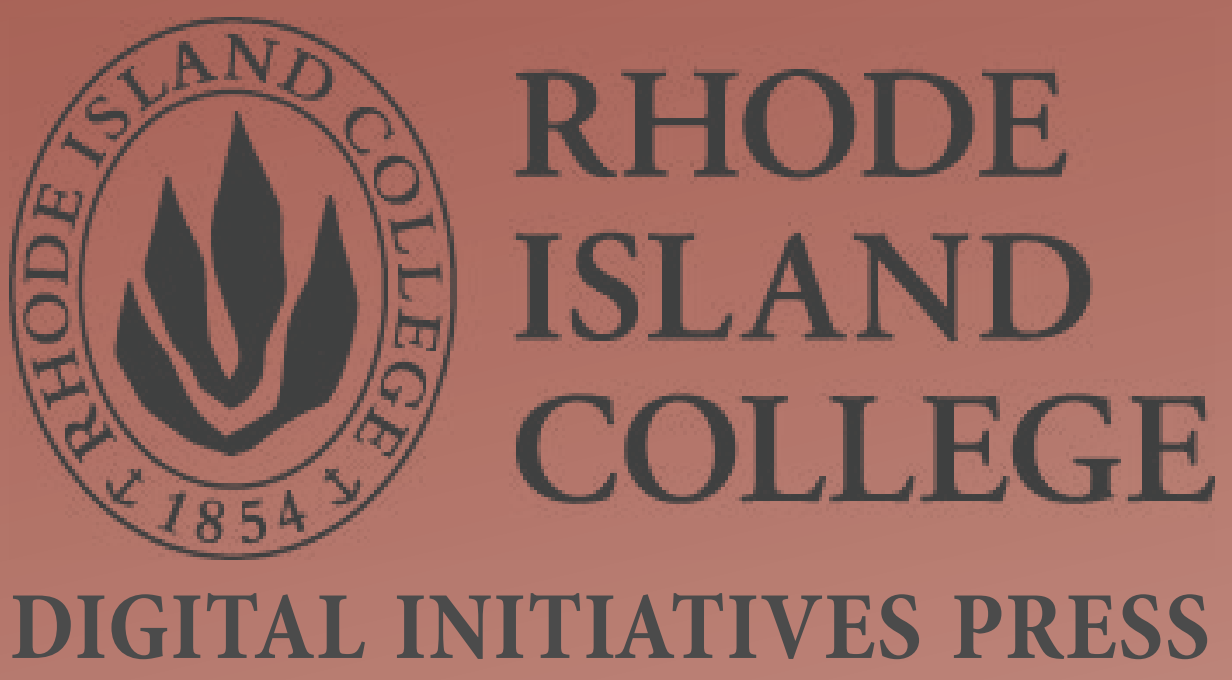




\section{Theoretical Frames and Teaching Styles of Physical Therapy Faculty Who Lead International Service-Learning Experiences}

Jennifer Gail Audette

Digital Initiatives Press: Rhode Island College

Providence 
Theoretical Frames and Teaching Styles of Physical Therapy Faculty Who Lead International Service-Learning

Experiences by Jennifer Gail Audette is licensed under a Creative Commons Attribution-NonCommercial-ShareAlike 3.0 Unported License. 
Purpose:

International service-learning (ISL) is popular in higher education, and many physical therapy educational programs are adding ISL opportunities to their curricula because doing so aligns with student interest and the increasingly global nature of the profession. The faculty leading these experiences have not been studied. Nearly all faculty in physical therapy programs are educated as therapists and not as teachers. Most do not have any background in pedagogical practice or educational theory.

The purpose of this study was to describe faculty leading ISL experiences in physical therapy educational programs and compare them to faculty who do not participate in ISL. Of specific interest were demographic variables, teaching style, and educational theoretical frames.

Method:

Data were collected using an online Faculty Survey. Responses from 205 physical therapy faculty subjects from across the United States were used for analysis. Forty seven (23\%) of these subjects reported having participated in international service-learning. Data from faculty who participate in ISL (Y-ISL) were compared to those of faculty who do not participate in ISL (N-ISL).

Analysis/Results:

When comparing the Y-ISL and the N-ISL groups in terms of their demographics using descriptive statistics, t-test analysis, or chi-square analysis differences were found only in age and years of practice. In terms of teaching style type (TST) - Expert/Formal Authority; Personal Model/Formal Authority/Delegator; Formal Authority/Delegator; Formal Authority/ Facilitator/Delegator; Delegator/ Facilitator, chi-square analysis results indicate that there is no significant association between TST and Y-ISL and N-ISL. When exploring the theoretical frame types (TFT); progressive, critical, and professional - chi-square analysis indicated that there is a significant association between TFT and Y-ISL and N-ISL. Y-ISL faculty are more likely than N-ISL faculty to come from a critical theory frame. Regression analysis resulted in a model that is unable to predict Y-ISL or N-ISL group membership based on faculty demographics, TST, and TFT.

\section{Discussion:}

The relevance of the study findings in relation to institutions of higher education, the field of physical therapy in general, physical therapy educational programs both with and without ISL programs and individual faculty are addressed. 
I would like to acknowledge several people who provided support and guidance during the coursework and research phases of my doctoral process.

I would first like to especially thank Dr. Susan Roush, who is a great friend, colleague, and mentor. Her attention to detail, support, feedback, and goal setting helped me to become a better writer, stay focused, and keep my eyes on the prize.

I would also like to express my gratitude to the other members of my dissertation committee, Dr. David Brell, Dr. Minsuk Shim, and Dr. Susan Gracia, for their interest, support, suggestions, and feedback. They pushed me to explore and understand the literature and the research process.

I would like to thank my mother, Gail Wheelock, for teaching me that - with hard work - anything is possible and for her terrific editorial feedback and support throughout the dissertation process.

I would like to acknowledge the support and good humor that Dr. Betty Young provided both in and out of the classroom.

I sincerely want to acknowledge the support of "The Gals of Cohort 2005": Sheila McGraw, Laura Chiaravalloti, Laura Falvey, and Janice Place. They are amazing women and the best cheerleaders anyone could ever have. I am proud to be in their company.

I would like to also acknowledge the many family members, friends, and colleagues who had me and my work in their thoughts and were always there to ask how things were going. 


\section{DEDICATION}

I would like to sincerely thank my husband, Michael, and my daughters, Castine, Gwendolyn, and Camille. I don't acknowledge often enough how much their love, support, and independence mean to me. This work is dedicated to them.

I would also like to dedicate this dissertation to the many students who have inspired me by reporting that their lives have been changed after participating in international service-learning opportunities. 


\section{Statement of the Problem}

International service-learning (ISL) is popular in higher education, and many physical therapy educational programs are adding ISL opportunities to their curricula (Pechak \& Thompson, 2009). Development of these ISL experiences aligns with student interest as well as the increasingly global nature of the profession (Koplan, Bond, Merson, Reddy, Rodriguez, Sewankambo, \& Wasserheit, 2009). Most of these ISL programs take place in developing nations (Pechack \&Thompson, 2009; Village, Clouton, Millar, Geigle, Okafor, Simuel, \& Uzarraga, 2004). Although some ISL student outcomes have been explored, the faculty leading these experiences have yet to be studied.

This focus on ISL and the provision of ISL opportunities for students in physical therapy education programs is due to a variety of factors. Globalization is influencing healthcare and physical therapists are likely to encounter marked diversity in any setting they work in. Therefore, providing opportunities for students to experience diversity and increase their cultural competence is critical. The number of people living with disabilities and other health issues relevant to physical therapists is also increasing (Sotnik \& Jezewski, 2005). One way to attempt to address these issues in academic programs is to provide ISL opportunities for students. ISL opportunities lead by faculty who have certain teaching styles and theoretical frames may help to develop skills and attributes in students that will enhance their preparation for practice in this culturally diverse and global health arena.

Based on the literature in higher education, the primary objectives of service-learning (SL) include improving students' clinical skills, encouraging a commitment to community service, reinforcing educational goals, improving civic awareness, and enhancing cross-cultural understanding. The opportunity to address additional objectives is presented when SL activities take place in a developing nation, although these objectives may vary depending on the experience and educational theoretical frame of the faculty leader.

As is seen throughout higher education, nearly all faculty in physical therapy programs are educated as therapists and not as teachers. Most do not have a background in pedagogical practice or educational theory. Consequently, faculty develop ISL experiences without consciously having a theoretical frame to guide them, and simply do the best they can based on their educational objectives and beliefs. Faculty who develop and lead ISL opportunities may have distinctive or unique theoretical frames, hopes for students, and/or teaching styles. For example, faculty who get involved in ISL may feel that they can achieve certain educational goals that cannot be met in the typical classroom setting.

The literature on ISL is limited. The more general topic, SL, has been explored in higher education in relation to student outcomes; however, there is a paucity of data describing SL faculty. In the SL and ISL physical therapy literature there are only a few studies (Beling, 2004; Dockter, 2004; Ganley \& Mueller, 2006, Goulet \& Owen-Smith, 2005; Hoppes, Bender, \& Degrace, 2005; Pechak \& Thompson, 2009; Reicherter \& Manual Williams, 2005; Reynolds, 2005; Village, Clouton, Millar, Geigle, Okafor, Simuel, \& Uzarraga, 2004), and none focus on SL faculty. Several notable authors in the field of $S \mathrm{~L}$ in higher education have pointed out the scarcity of research exploring faculty. Bringle and Hatcher (1995, 1996, 2000), Driscoll (2000), Driscoll, Holland, Gelmon, and Kerrigan (1996), Eyler and Giles (1997), Gelmon (2000), Gelmon, Holland, Driscoll, Spring, and Kerrigan (2002), Kahne, Westheimer and Rogers (2000), Palomba and Banta (1999), and others (Bradley, 1997; Hammond, 1994; Hesser, 1995; Serow, 1997) have all discussed the need to know more about the faculty involved in SL and ISL.

\section{Justification}

The purpose of this study was to describe faculty who lead ISL experiences in physical therapy educational programs and compare them to faculty who do not participate in ISL. Of specific interest were 1) demographic variables including age, gender, degree, faculty position, years as a physical therapist, and years teaching, 2) teaching styles as defined by Grasha and Riechmann (1996), and 3) educational theoretical frames: a. progressive theory, b. critical pedagogy theory, and c. professional theory.

The following research questions were addressed:

- Do ISL and non-ISL faculty differ on demographic variables?

- What are the teaching styles and theoretical frames of faculty who carry out ISL in physical therapy education and those who do not? Are there differences between groups?

- What is the relationship between teaching style and theoretical frame and participation in ISL?

This study is salient because it builds on what is presently known about SL in general, and ISL specifically, and advances the literature in the previously unstudied area of physical therapy faculty. This study is important and unique because it provides information that deepens a very shallow pool of knowledge in the area of ISL. The specific area of interest, 
physical therapy faculty leading ISL experiences, is unexamined. Indeed, in physical therapy, no study has explored faculty variables in any realm of ISL. The findings from this study are of interest to many stakeholders, including all institutions of higher education, the physical therapy profession, physical therapy educational programs, program faculty, students, and educational accreditation agencies.

For institutions of higher education the study provides data to support the improved understanding of faculty and understanding of faculty involvement in ISL. It may help to support teaching and program development by grounding mentor and orientation programs with theory about teaching styles.

The study also provides valuable data for the field of physical therapy. The $21^{\text {st }}$ century has seen the profession of physical therapy taking a more global stance and positioning itself for enhanced international awareness and collaboration (APTA, 2009). Any research that combines physical therapy and international topics can inform this movement. Data from this study will also be of interest to physical therapy educational programs and their faculties, as it adds to the body of knowledge related to effective and dynamic teaching, overall awareness and understanding of ISL, insight and understanding about educational theory and its connections to ISL pedagogy, program cost-benefit analyses, and identifying faculty best-suited for ISL. For educational programs, the demographic data collected in this study provide a profile of faculty who are participating in ISL. This information does not exist in the literature and will likely be of interest to physical therapy program directors, accrediting agencies, the American Physical Therapy Association (APTA), faculty, students, and professional special interest groups like the APTA Cross Cultural and International Special Interest Group, recently renamed the Global Health Special Interest Group (2011).

Additionally, accrediting bodies may value the data for its ability to enhance accreditation criteria and standards through better understanding of educational theory and teaching frames. Particularly in the area of professional attribute standards such as accountability, altruism, compassion and caring, integrity, duty, and cultural competence. Better understating about what ISL looks like in physical therapy may benefit the field by providing information that could be used to market certain aspects of the profession.

For physical therapy educational programs the study is valuable in a variety of ways. The information can be used to create a framework for considering faculty teaching styles and theoretical frames as they relate to professional development, addressing and discussing achievement of student outcomes, and using a common language for the discussion of educational issues and student and faculty performance. The study also can be used to support program missions and teaching philosophies. Additionally, the data can be used to legitimize classroom conversations about topics that might be overlooked in a typical curriculum or considered too controversial in the context of physical therapist education.

For individual faculty the study is valuable because it provides a framework for thinking about and reflecting on practice in terms of teaching style and educational theory. For faculty who enter academia without any formal training in education it may be eye-opening to discover an entire body of scholarship devoted to educational theories, teaching, and student outcomes. All faculty can benefit from improved understanding of the most effective teaching practices and styles that work best in the classroom. Faculty will benefit from an improved understanding of highly regarded educational theory. Faculty will be better able to integrate the improved understanding of teaching styles and educational theory into their practices and into the classroom.

With a better understanding of the theoretical frameworks from which they are conducting ISL, faculty members will benefit from the study because it will improve their insights into their teaching, and provide them with a theory to support ISL strategies, goals, and objectives. It may also provide an evidence-based foundation from which they can advocate for expanded support of ISL programs. The following review of literature supports the importance of these research questions. 


\section{Overview}

In this chapter several areas of the literature relevant to this study will be explored. In Section 1, literature regarding $\mathrm{SL}$ as pedagogy in higher education will be introduced. This section will also include literature related to the implementation of SL, associated student outcomes, and faculty involvement. Section 2 of the literature review will address service-learning as pedagogy in physical therapy. Section 3 overviews ISL from two perspectives: first, in higher education, and second, in physical therapy. Section 4 covers the literature specific to the variables of interest in this study, namely teaching styles and educational theory. Focus on the latter includes progressive theory, critical pedagogy theory, and professional theory literature.

\section{Section 1: Service-Learning as Pedagogy in Higher education}

Many prominent educational theorists and researchers have explored important pedagogical issues associated with SL at the college level. These pedagogical considerations include authenticity, encouragement of higher order thinking, theoretic support for the use of SL in higher education, and reflection activities. While this literature is not necessarily specific to ISL, much of it is applicable to ISL experiences. The first topic to be considered is authenticity. Magnuson and Palincsar (1995) emphasized the value of learning experiences that are "authentic" and true to life. Other theorists have reiterated the importance of meaningful and authentic learning experiences, and have expressed that features such as challenge, emotion, internalization of experiences, and teamwork enhance the SL experience (Bringle \& Hatcher, 1995; Brown, 1987; Donaldson, 1978; Fosnot, 1996; Hofer \& Pintrich, 1997; Kohlberg \& Mayer, 1972; Lincoln, 1992).

A second feature of SL addressed in the literature is higher order thinking. Several authors cite the importance of teaching in ways that enhance these skills, including critical thinking and problem solving abilities (Kahne \& Westheimer, 1996; Lewis \& Smith, 1993; Underbakke, Borg, \& Peterson, 1993). According to this literature, higher order thinking is fostered when learners are active participants in learning situations in which simple recall of information is not enough. Further, meaningful learning requires "thinking dispositions" such as metacognition, reasoning, broad and adventurous thinking, and intellectual curiosity (Tishman, Jay, \& Perkins, 1993). These "thinking dispositions" are considered critical to productive intellectual behavior.

While there is less literature related to the third SL feature of interest, theoretical support, Hofer and Pintrich (1997) provide valuable insight. They reviewed two epistemological theories that support SL philosophy and curriculum. First, they considered Perry's Scheme of Intellectual and Ethical Development (Perry, 1970) which identifies the highest level of development as "commitment within relativism." This is when a learning experience allows individuals to make and affirm commitments to values, careers, relationships, and personal identity. Second, they reviewed King and Kitchener's Reflective Judgment Model (King \& Kitchener, 1994), which is based on research and experience with college students. The Reflective Judgment Model identifies reasoning and reflective judgment as the highest level of intellectual development. A person at this level can construct knowledge, give contextual meaning, and reevaluate judgments that they have made. According to Seifer (1998), the integration of meaningful community service which includes instruction that connects the service activity to classroom content is central to SL as a teaching and learning strategy at all levels of education. Making clear links and connections to course content helps to enrich the learning experience, teach civic responsibility, and strengthen campus-community partnerships. Kahne and Westheimer (1996, p. 593) also emphasize the importance of SL as a way to "invigorate the classroom [and provide] rich educational experiences for students at all levels of schooling." In the conclusion they identify three main goals that should be supported and aspired to through higher education SL activities: deepening of connections and relationships, enhancement of social awareness, and transformation related to disciplinary knowledge and social engagement.

The fourth SL feature to be addressed here is reflection. It is striking that most definitions of SL include reflection as a vital component, and Hatcher and Bringle (1997) provide specific guidelines for reflective writing associated with SL.

The importance of reflection was originally noted by Dewey. In How We Think: A Restatement of the Relation of Reflective Thinking to the Educative Process (1933), Dewey discussed the idea that learning by doing is not enough and that students must reflect on the controversy and challenges created during the experience. Empirical research also supports the salience of reflection as a key component of SL (Ash, Clayton, \& Atkinson, 2005; Hatcher, Bringle, \& Muthiah, 2004). Hatcher, Bringle and Muthiah (2004) carried out a mixed methods study with 471 faculty subjects at nine Indiana universities to look at pedagogy and how reflection on SL was being implemented. Their findings show that reflection is most productive when it is structured and included as a regular part of the SL experience. Additionally, they found that reflection helped to clarify students' personal values. Ash, Clayton, and Atkinson (2005) found that higher order reasoning and critical thinking were positively associated with the use of reflection.

Finally, several vital aspects of SL campus-community partnerships have been identified. Key features include partnerships where there is mutual respect, equal power, and true reciprocity. The importance of strong, reciprocal, and sustainable campus-community partnerships is emphasized by several authors exploring SL in both noninternational settings (Fenzel, \& Peyrot, 2005) and international settings (Kiely, \& Nielson, 2003; Myers-Lipton, 1996; Parker, 
\& Dautoff, 2007; Porter, \& Monard, 2001; Riner, \& Becklenberg, 2001; Silcox, \& Sweeney, 1993; Williams, \& Eiserman, 1997).

\section{Student Outcomes of Service-Learning}

In addition to the student outcomes associated with SL reflection (as described above), other student outcome literature exists. Cooks and Scharrer (2006) and Lowery, May, Duchane, Coulter-Kern, De' Bryant, Morris, Pomery, and Bellner (2006) report positive SL educational outcomes and support the use of SL as a component of higher education. In 1996, using case studies, Driscoll, Holland, Gelmon, and Kerrigan studied the general impact of SL on students and found positive outcomes related to personal growth.

Eyler, Giles, and Braxton (1997) carried out a mixed methods study to explore the pre- and post- citizenship levels of 1,500 students at 20 different colleges. They compared subjects who had participated in SL to subjects who had not participated in SL. They found that, over a semester, students who participated in SL had higher levels of skill, perception, value, and understanding related to social issues than their peers who did not participate in SL. Similarly, in a 2004 study, Brody and Wright explored the service attitudes and behaviors of 277 college graduates. They found that those subjects who had participated in SL activities during their undergraduate career had higher levels of participation in service activities after graduation from college than did those students who did not participate in SL. Kendrick (1996) used a self-developed survey to look at the social responsibility levels of 123 psychology students. He found that social responsibility levels were higher in students who had SL as part of their course work. Finally, Miller (1997) gave pre- and post- surveys to 327 psychology students who participated in SL and found that SL had positive effects on students' perceptions of power and self-advocacy.

While there is a clear body of evidence documenting differences between students who did and did not participate in SL, it is unknown if these differences were the result of the SL experiences or were pre-existing. Indeed, students who choose to participate in SL may be fundamentally different from students who do not pursue this experience, suggesting that the internal validity of these studies may be weak. However, even in studies that compared courses where students did not voluntarily choose SL, positive outcomes were evident in the SL groups. For instance, a study by Miller (1994) suggests that SL may improve the application of course concepts that require real-world practice. In that study 35 psychology students were surveyed about their experiences in a course that was offered in two formats, one with and one without SL. Students were unaware of the difference in the two courses. Students who participated in the course with SL qualitatively reported higher levels of application of course concepts in real world situations than those who did not participate in SL.

\section{Faculty Involvement in Service-Learning}

Although there is a fair amount of literature on SL student outcomes in higher education, there is much less known about SL faculty. In a review of the available related literature, Driscoll (2000) remarked about the lack of information about SL faculty. He suggested that SL faculty have an adequate understanding of the integral aspects of SL, SUch as cohesive and integrated implementation of SL projects with course curriculum, strong community partnerships, reflective activities, appropriate student supervision, and course assessments, but he expressed a need for additional research related to broader aspects of faculty involvement in SL.

Most often the impact of SL on faculty has been studied. A review of the literature in this area indicates that not all of SL's impact on faculty is positive. Some studies found that potential negatives include an increased time commitment, difficulty in assessing student performance, and the inherent introduction of value-laden topics which might cause controversy in the classroom. In 1994, Levine proposed guidelines for universities to improve the amount and quality of faculty involvement in SL based on his experience and knowledge of SL. His guidelines included providing adequate financial support for projects, facilitating faculty continuing education in SL, using a variety of concepts of "service," connecting SL to research, and rewarding SL efforts.

Qualitative studies have been carried out to investigate why faculty get involved in SL and to explore the impact of SL implementation on faculty workload and teaching (Braskamp, 2008; Driscoll, Holland, Gelmon, \& Kerrigan, 1996; Hammond, 1994; Harwood, Ochs, Currier, Duke, Hammond, Moulds, Stout, \& Werder, 2005; McKay \& Rozee, 2004; Pribbenow, 2005). SL impact on faculty has been found to be wide-ranging. The qualitative data from these studies illustrate that adding an SL component to a course increases the faculty workload and requires teaching adaptations to connect service to classroom content.

Even though SL has been identified by some faculty as being cumbersome, faculty who choose to implement SL identify varied motivators and many benefits. In 1994, Hammond looked quantitatively at the motivation for carrying out SL and satisfaction levels of 130 university faculty who use SL. He found three predominant categories of motivators: personal, co-curricular, and curricular. The personal motivators include faculties' own past involvement in service, enjoying service themselves, acting toward social change, working with students outside the classroom, and an interest in helping those in need. Faculty co-curricular motivators include promotion of civic involvement, moral character development in students, and improved multicultural understanding. Curricular motivators were things such as effective 
presentation of content material, encouragement of self-directed learning, professional training, and experiential application of content.

In an essay written following conversations with faculty and college administrators from across the globe, however, Braskamp (2008) found that SL-related 'costs,' are reported to be far outweighed by the benefits of SL, which include the development of global citizenship and an understanding of common good, justice, equity, and fairness in students.

In 2007 Banerjee and Hausafus studied a group of 368 human science faculty, some who incorporated SL in their courses (58\%) and some who did not (42\%). They found that a majority of those who utilized SL identified it as a valuable tool for teaching and learning. E.g., 59\% perceived improved student understanding of course material, and $48 \%$ reported improved student personal development. More recently, O'Meara and Niehaus (2009) studied the nomination files of 109 "exemplary" faculty who were 2002 - 2005 nominees for the prestigious Campus Compact Thomas Ehrlich Faculty Award. Their purpose was to explore why these exemplary faculty implemented SL with their students. All (100\%) exemplary faculty subjects said they used SL because of its teaching and learning benefits and the experiential components. Additionally, the data from this qualitative study indicate that faculty identified four common purposes for using SL. The first, and considered by the faculty to be by far the most important purpose, was that SL provided a positive model for teaching and learning (89\%). Secondly, subjects reported that SL provided an opportunity for students' expression of personal identity (45\%). Thirdly, faculty identified SL as being an expression of the institutional mission and values (36\%). Lastly, SL was perceived to be beneficial because it fostered community partnerships (18\%). Another finding of the O'Meara and Niehaus (2009) study was that $53 \%$ of the "exemplary" SL faculty surveyed identified that they used SL to shape the civic and moral dispositions of students.

In another aspect of faculty involvement in SL, Hesser (1995) surveyed 48 college faculty qualitatively about their perception of students' SL outcomes. Based on percentage responses, the author reported that a majority of subjects studied felt that there were "extensive" improvements in students' abilities to critically reflect on their values and biases and to think critically and analytically. Faculty, however, reported little change in students' ultimate understanding of course concepts.

While much of the literature in SL has utilized qualitative methodology or has been limited by small sample sizes, large quantitative studies addressing factors that influence faculty's utilization of SL have also been carried out. In the 518 faculty that Abes, Jackson, and Jones (2002) studied, they found that the major deterrents to the use of SL by faculty were the amount of time involved, the difficulty in coordinating activities, and securing funding. When Village, Clouten, Millar, Geigle, Okafor, Simuel, and Uzarraga (2004) surveyed physical therapy faculty, they found similar results. They reported that although many physical therapy and physical therapy assistant (PTA) programs have SL components, some directors were hesitant to formally include SL because it is not a necessary part of the accreditation-driven curriculum, it is costly, and faculty lack interest.

None the less, in most cases faculty subjects reported spending increased time and effort on courses with SL components, nearly all reported that it was worthwhile.

\section{Section 2: Service-Learning as Pedagogy in Physical Therapy}

There is a small body of literature related to $S L$ in physical therapy education. Again, student outcomes, including critical thinking skills (Beling, 2004), general impact (Ganley \& Mueller, 2006), and professionalism factors (Reynolds, 2005) have been the primary focus of this work. Goulet and Owen-Smith (2005) endorsed SL experiences as an explicit way to address affective learning with physical therapy students. In 2004, Beling used the Watson-Glaser Critical Thinking Appraisal and a Facts on Aging Quiz to pre- and post- test 40 students who all took the same geriatrics course. Based on random section assignments, 20 of the students had an SL component to the course and 20 did not. Pre and post data from the Facts on Aging Quiz indicate that SL students had developed personal relationships with their geriatric clients that improved their attitudes regarding geriatric physical therapy. Beling did not, however, identify differences in critical-thinking skills between the two groups.

Ganley and Mueller (2006) used a combination of interviews and an objective rating scale to study a small group $(n=12)$ of physical therapy students during a local SL project in a pediatric setting. In this descriptive study, subjects reported positive learning outcomes and experiences, although these findings could not be specifically associated with the SL experience. Reynolds (2005) carried out a qualitative study of 85 students to assess the impact of SL on factors related to professionalism. She carried out content analysis of written reflections and observational data and related it to the clinical practice expectations from the Clinical Performance Instrument (CPI). The CPI is the standardized tool used across the country by clinical instructors to assess the performance of students during their clinical practice placements. When looking at the data from the SL participants' reflective writing samples, CPI criteria related to social responsibility, prevention and wellness, consultation, and referral issues were addressed more often than in the reflective writings of students who did not participate in SL.

Pedagogy and SL implementation in allied health professions have been a focus of some authors, although, again, rigorous study is lacking. In an essay, Hoppes, Bender, and Degrace (2005) discussed the value of implementing SL in 
physical and occupational therapy programs. They highlighted aspects of SL that include community contribution, optimizing professional preparation, application of classroom content, and reflection. Reicherter and Manual Williams (2005) offer a case study exploring the positive benefits for the elderly recipients of a physical therapy SL program in an urban setting. These benefits include reports of improved quality of life. Village, Clouton, Millar, Geigle, Okafor, Simuel, and Uzarraga (2004) explored the use of SL, pro-bono, and volunteer programs in physical therapy programs nationally. Using aggregated survey data from faculty in 217 physical therapist and physical therapist assistant programs, they found that a majority (77\% of PT, 61\% of PTA) of programs were using at least one of these types of service activities. Of those, about $80 \%$ were using SL and reported that their primary goals related to student learning and community benefitted.

\section{Section 3: International Service-Learning in Higher Education}

The first two sections of this chapter address SL in general. This section specifically addresses ISL, first in higher education in general then ISL specific to physical therapy professional education. The general importance of international service opportunities for students in higher education has been presented by several authors (Chisholm, 2003; Craft, 2002; Hartman \& Rola, 2000; Silcox \& Leek, 1997). Ideas about how to develop and implement international partnerships (Grusky, 2000; Patterson, 2000; Riner \& Becklenberg, 2001; Silcox \& Sweeney, 1993), and how to mentor students during ISL (Roberts, 2000) have also been introduced in the literature. Keith (2005) addressed important aspects of globalization that should be considered when planning ISL opportunities for students. Taken together, the above studies suggest that faculty need to carefully consider elements critical to the success and sustainability of ISL opportunities, including strong campus-community relations, excellent student mentoring and support, and an understanding of global issues and influences.

In comparison to SL research, ISL literature is more often concerned with student outcomes; ISL research also tends to be limited by small sample sizes. Kiely (2004) carried out a longitudinal case study related to an ISL experience of 22 U.S. students who participated in an ISL experience in Nicaragua. Using document analysis and semi-structured interviews, he found that these students reported profound changes in their world-view of political, moral, intellectual, personal, spiritual, and cultural issues. Pyle (1981), Stachowski and Visconti (1998), Porter and Monard (2001), Parker and Dautoff (2007), and King (2004) also used qualitative methodology and documented self-reported increased levels of critical inquiry and self-examination, as well as improvements in intellectual growth and maturity, and relationship-building after ISL experiences.

\section{International Service-Learning in Physical Therapy}

The ISL literature in physical therapy is limited to two studies. First, Dockter (2004) studied student outcomes, and later Pechak and Thompson (2009) looked at the prominence and development of ISL in physical therapy educational programs. In Dockter's (2004) dissertation research, she utilized qualitative data gathered from 25 students, including 12 who had just returned from an ISL trip to Guatemala and 13 peers who had not participated in ISL. Based on data from pre- and post- interviews and surveys, she found that the students who participated in the ISL experience had higher levels of political awareness, interpersonal skills, and problem-solving skills. No distinction could be made between effects caused by the ISL experience and self-selection. Second, in survey responses from 95 out of 210 PT education program directors in the US and Canada, Pechak and Thompson (2009) identified that nearly $43 \%$ of programs had ISL components, and $14 \%$ of the programs that did not have ISL reported that they would be adding ISL in the next two years. The faculty who did ISL found it to be beneficial for themselves and for students. Faculty reported that ISL enhanced the physical therapists' role in the global health arenas and supported the APTA's core professional values of Social Responsibility, Altruism, and Professional Duty (American Physical Therapy Association accessed 10/4/10 at www.apta.org). Although these physical therapy ISL studies are seminal in the profession, specific faculty characteristics of ISL faculty were beyond their scopes.

\section{Section 4: Variables of Interest in this Study}

In addition to SL- and ISL-specific literature, learning styles and educational theories are variables of interest in this study. Relevant literature on each variable is described in this section.

\section{Teaching Style}

The first primary faculty characteristic of interest in this study is teaching style. Teaching styles are a combination of qualities, needs, beliefs, and behaviors that faculty display in the classroom and that are important in guiding and directing the way teachers teach (Grasha, 1996). Grasha is the predominant author associated with teaching styles, and he has published individual work as well as work with collaborators (Grasha, 1994, 1994, 1996; Grasha, \& Riechmann-Hruska, 1996; Grasha, Silver, Hanson, Strong, \& Schwartz, 1996). Teaching styles vary in degrees and are often blended together in practice; therefore it is difficult, and inappropriate from Grasha's view, to identify someone as having only one specific style type.

Several teaching style inventories exist. Silver, Hanson, Strong, and Schwartz (1996) developed a measurement tool; however, there is minimal reference to this tool in the literature. A commercial product, the 4MAT® Teaching Style 
Inventory (TSI), exists on line (http://www.aboutlearning.com/index.php/learning-assessments/teaching-styles-inventory). It is a 30 minute questionnaire that assigns each respondent to one of four teaching style quadrants. The TSI appears to be more suited for use by elementary school educators than to higher education faculty. Another tool, the CORD(C) Teaching Styles Inventory (2007), has respondents rank four choices in each of 12 questions. The results are presented graphically in relationship to two axes: "Teaching Goals" and "Teaching Methods." None of these three tools seemed optimal for this study.

The most frequently used tool appears to be the Teaching Style Survey developed by Grasha and Riechmann-Hruska (copyright 1976, 1987, 1990, 1996). This survey is a 40 item Likert scale that was developed for use by college teachers and is based on the work of Grasha over the course of his career. The Teaching Style Survey categorizes respondents into one of five teaching style types which Grasha identified in his 1996 book, Teaching with Style. These types are 1) expert, 2) formal authority, 3) personal model, 4) facilitator, and 5) delegator. While this tool has been used extensively, reliability and validity data are unavailable either in the literature or from the authors. A description of the five teaching style types follows:

Expert This teacher is a transmitter of information who possesses knowledge that students need and strives to maintain his/her status as an expert among students by displaying detailed knowledge and by challenging students to enhance their competence. Experts are concerned with transmitting information and ensuring student preparation. The advantages of this style are that the teacher is seen to possess information, knowledge, and skills. A disadvantage of this style is that an overt display of knowledge can be intimidating to inexperienced students, and the underlying thought processes that produced the information may not be clear to learners.

Formal Authority This teacher sets standards and defines acceptable ways of doing things. This instructor possesses status among students because of knowledge and role. These teachers are concerned with providing positive and negative feedback, establishing learning goals, expectations, and rules of conduct for students. They are also concerned with correct, acceptable, and standard ways of doing things. The advantage of this style is a focus on clear expectations and acceptable ways of doing things; however, this style can lead to rigid, standardized ways of managing students and their concerns.

Personal Model This teacher teaches by illustration and direct example. He or she believes in teaching by personal example and establishes a prototype for how to think and behave. Students are encouraged to observe and emulate the instructor's approach while the teacher oversees, guides, and directs. The benefits of this style are the hands-on nature of the approach and an emphasis on direct observation and following a role mode; however, some teachers may believe that their approach is the best way, leading some students to feel inadequate if they cannot live up to such expectations and standards.

Facilitator This type of teacher guides and directs by asking questions, exploring options, and suggesting alternatives. He or she emphasizes the personal nature of teacher-student interactions and encourages students to develop criteria to make informed choices. The facilitator's overall goal for students is that they develop the capacity for independent action and responsibility. He or she works with students on projects in a consultative manner and provides much support and encouragement. The advantages of this style are the personal flexibility, the focus on students' needs and goals, and the willingness to explore options and alternative courses of action to achieve them; however, this style is often time consuming and can be ineffective when a more direct approach is needed. It can also make students uncomfortable if it is not used in a positive and affirming way.

Delegator This teacher focuses on developing students' ability to function autonomously. Students work independently on projects or as part of autonomous teams. The teacher is available as a resource person at the request of students. This style contributes to students' perceiving themselves as independent learners. A negative aspect of this style is that teachers using this style may misread students' readiness to work independently. Some students may become anxious when given autonomy.

According to Grasha, no one style is better or worse than another, and the types are not mutually exclusive. He cautions against placing a teacher in only one of the five types. Instead Grasha acknowledges that each style has its advantages and disadvantages, and he advocates teachers possess each of the five teaching styles and blend them together in practice. He suggests that four clusters emerge as appropriate categorizations of style: Cluster 1: Expert/ Formal Authority, Cluster, 2: Personal Model/Expert/Formal Authority, Cluster 3: Facilitator/Personal Model/Expert, Cluster 4: Delegator/Facilitator/Expert. Grasha (1996) found that these teaching style clusters are distributed among university faculty (across many disciplines) as presented in Table 1. 


\begin{tabular}{|c|c|}
\hline Cluster & Percent of Faculty \\
\hline Cluster 1: Expert/Formal Authority & $40 \%$ \\
\hline Cluster 2: Personal Model/Expert/Formal & $24 \%$ \\
Authority & $19 \%$ \\
\hline Cluster 3: Facilitator/Personal Model/Expert & $17 \%$ \\
\hline Cluster 4: Delegator/Facilitator/Expert. &
\end{tabular}

\section{Theory: Progressive, Critical, Professional}

The second variable of interest is faculty educational theoretical frame. The theoretical perspectives to be considered in this study are the progressive perspective of John Dewey (Deans, 1999; Giles \& Eyler, 1994; Hatcher, 1997), the critical pedagogy perspective of Paolo Freire (Deans, 1999), and the professional perspective of Pamela Reynolds (2005). The work of these scholars has been chosen because their writing crosses into the SL literature most predominantly. A 1999 article by Deans provides a valuable comparison of Dewey's and Freire's ideas, and this work has helped to shape this section of the literature review. The three theoretical perspectives will be reviewed moving from Dewey's progressivist theory to Freire's critical pedagogy and finally to Reynolds and her professional theory approach. These three theoretical frames are complementary, yet they serve as the foundation for diverse ways of thinking about and interacting with students, and developing courses and learning objectives.

The theoretical literature in education is vast. While much of that literature is specific to children, the educational topics addressed are relevant to all learners, regardless of age. Within the SL literature, authors debate the associated theoretical frames and refer to various educational theorists including Dewey (Deans, 1999; Giles \& Eyler, 1994; Hatcher, 1997), Freire (Deans, 1999), and Jane Addams (Danes \& Longo, 2004). Each of these theorists has been identified in the literature as providing a theoretical framework for SL. The premier journal for SL literature is the Michigan Journal of Community Service Learning, and the work of each of these authors has been published in that journal. Dewey's influence has been studied in some depth by Deans (1999), Giles and Eyler, (1994), and Hatcher (1997). Freire is less thoroughly discussed in the SL literature (Deans, 1999) but is widely discussed in more general educational works. Although her influence will not be studied in this research, it is important to acknowledge that Jane Addams is also connected to the SL theoretical literature by Danes and Longo (2004). In their work, Addams is seen as a contributor to SL because of her early $20^{\text {th }}$ century focus on bringing academia into the community and creating and developing campus and community partnerships.

\section{Progressive Theory}

Progressivism has had major impacts on educational thinking and practice. Progressivist authors see education as a developmental and progressive process. The student is seen as a problem-solver who will develop increased understanding and control over learning in educational settings. For progressivists the ultimate goal of education is to empower students to become autonomous, democratic citizens. John Dewey $(1859-1952)$ is regarded as the father of progressive theory. Over the course of his professional career he espoused "instrumentalism," a belief that thinking is an activity which, at its best, is directed toward resolving problems.

His vast body of literature expands on the notions that behavior is shaped by habit and that change produces conflict which leads to creative thinking in order to try to reestablish control of the changing environment. Dewey believed that a person's thoughts were directly related to context and surroundings and that a person's learning environment influenced his/her learning and creativity. Dewey believed in democracy and that education for all was the way to true democracy. The "progressive education" movement of the 1920s was based on Dewey's ideas.

Dewey noticeably did not address issues of race, culture, or ethnicity, and he had little to say about multiculturalism (Deans, 1999). Because of his strong beliefe in building community, at times Dewey's work takes on a Marxist tone however; he was interested in gradual "social reconstruction" within a capitalist system, rather than revolution (Deans, 1999).

John Dewey (1916) believed that students learn best through experiences that are meaningful and by solving problems in real-life situations. The pedagogical implications of Dewey's work are seen in experiential learning curricula (Dewey, 1938; Kolb, 1984) which was the forerunner of service-learning as pedagogy.

Piaget and other "progressive-developmental" theorists are also considered relevant to SL. But Dewey is most frequently referred to in the SL literature and set the stage for those who followed in his footsteps. Piaget (1964) supported a developmental model for learning, although Dewey was suspicious of this idea and did not include a developmental component in his ideas. Building on both Piaget's and Dewey's ideas, Kohlberg and Mayer (1972) focused on the interaction of the student with real-life environments, problems, and challenges. Like Dewey, Kohlberg and Mayer believed that educational progressivism is characterized by the construction of knowledge though providing students with problems to solve in cooperative and democratic work groups. Following Dewy, they also advocated for connecting problem-solving activities and community problems when possible. Kohlberg and Mayer (1972) also stressed the importance of discourse and conversation and how it strengthens the link between cognitive 
development and moral development. A more comprehensive discussion of Kohlberg and Mayer's work is beyond the scope of the present study. Although many theorists have been influenced by Dewey, he directly and indirectly continues to stand out as one of the primary theorists relevant to SL. Because of this his educational frame was used to inform this study.

For the purpose of this study, educators interested in providing a responsive curriculum that produces students with the knowledge, interests, habits, and power to shape themselves and society are progressivists. Dewey influenced them and began to contribute to the progressivist frame that surrounds ISL. Progressivists believe that teaching should be student-centered and based on functional, individual experience. Active problem-solving (Rogers in Monte \& Sollod, 2003), social interaction, culture (context), and learner readiness for the construction of meaning (Fosnot, 1996; Piaget, 1964; Vygotsky, 1968) are highlights of this approach.

To summarize, the main features of a progressivist theoretical frame are relevant to and provide a lens for exploration of SL and ISL topics. Deweyan theorists see education as a progressive process. The student is seen as a problem-solver who will develop his/her own increased understanding and control over learning. They also believe that democratic procedures should be used in the classroom or learning environment. The way to achieve this goal is to provide learning experiences that are meaningful and allow for solving challenges and problems in real-life situations and environments. Progressivists feel that educational situations like these stimulate active thinking and problem solving. Additionally, progressivists stress the importance of social interaction, discourse, and conversation and how these elements strengthen the link between cognitive development and moral development. Educators should draw on the individual talents and capabilities of students. It should be noted, however, that the importance of the studentcentered nature of progressive pedagogy is mitigated by the importance of the social context and the autonomous, cooperative, and democratic habits of thought that encompass progressive pedagogy and learning. Progressivists do not leave students to their own devices; rather they provide context and structure that allows students' individual strengths to emerge and develop within a democratic system. The belief of progressivists is that context and structure should also lead the student to discovery and learning.

Not only do progressivists value the importance of active experimentation and problem solving, they also emphasize action followed by reflection. Progressivists see reflecting on activities as an integral part of the learning process because it makes learning experiences personal and provides an opportunity for individual construction of meaning and autonomy.

\section{Critical Pedagogy Theory}

Critical pedagogy theory has also greatly influenced educational thinking and practice. Critical pedagogues base their ideas in varying degrees on the work of Karl Marx, who was a communist concerned with the rights of workers during the mid to late $19^{\text {th }}$ century. Critical pedagogy arose in the middle of the $20^{\text {th }}$ century in reaction to world events and educational practices. Critical pedagogy theory is an educational movement that is intended to help students develop awareness and consciousness about issues such as social injustice, freedom, and authoritarianism. Students are expected to consider power relationships and to think about how to take active measures to right injustices. Critical educators tend to be guided by strong principles and passions (Giroux, 2010). The primary originator of critical pedagogy is Paulo Freire.

Freire criticized those educators who supported a "banking" model of education and rejected their notions that students were empty vessels waiting to be filled by their teachers. He disliked the idea of a teacher-student dichotomy and preferred the idea of reciprocity between teachers and students. Like Dewey, he believed that learning is an active process. Additionally, Freire was deeply interested in issues of diversity and culture and how education addressed those issues (Simon, 2006). Freire, however, took this one step farther and laid the groundwork for what is now known as "critical pedagogy." Critical pedagogues see students as emerging activists who should criticize accepted power structures and ideas. Learning is seen as the development of increased praxis, the ability to enact or practice a skill to transform social, cultural, and political environments to achieve social justice. These theorists believe in teaching that empowers, raises consciousness, and responds to social issues and needs. They feel students should be led to experience and to acknowledge problems in society. To critical pedagogues, education and therefore educators, should be involved in working toward morality, social justice, and democracy. Critical pedagogues see education as an opportunity for students to challenge the status quo.

Educators who aspire to critical pedagogy use current world examples to elicit reaction to world events. For them, students are activists who should be encouraged to criticize accepted power structures and ideas. The practice of posing problems, known as "problematizing," is integral, and the problems posed should reflect real world issues, particularly problems of social justice, to raise social consciousness. Students should be educated in a way that encourages the development of abilities to transform environments to achieve social justice. Educators who embrace the ideas of critical pedagogy empower students by raising their consciousness and prompting them to respond to social issues and needs, to challenge the status quo, and to question power relationships. 
citizens. From this perspective, educators should take an anthropological perspective and make use of the socioeconomic, racial, and cultural differences of the students. Like the progressivist, the critical pedagogue believes that uneasiness and uncertainty in students is a good thing and that it will promote learning, action, and further inquiry. Like progressivists, critical pedagogues also value reflection and stress that students should act, reflect, then act again based on that reflection. However, unlike progressivists, critical pedagogues focus particularly on the righting of social wrongs. Ultimately, critical pedagogues seek transformation. They see education as political and feel that education should be used to examine the myths and values of mass culture and society.

\section{Professional Theory}

In professional education the focus is on learning skills and developing professional attributes that are needed in future employment settings; the nature of professional education necessitates a major focus on these two areas. Literature in the field of physical therapy tends to be practical and focused on education as a means of producing clinically competent practitioners. This focus and the associated literature are driven by the guidelines and standards set by the American Physical Therapy Association (APTA) and other allied health professional organizations, by the Commission on Accreditation of Physical Therapy Education (CAPTE), and students' clinical placement requirements.

In the field of physical therapy, Pamela Reynolds (2005) researched professional development as it relates to SL. She asserts that professional skills that are difficult to teach in a classroom setting can be addressed through servicelearning as long as it is well-integrated into curricula. Although Reynolds is not an educational theorist per se, her 2005 article, How Service Learning Experiences Benefit Physical Therapy Students' Professional Development: A Grounded Theory Study, illustrates her educational perspective as it relates to the education of physical therapists. The purpose of this 2005 qualitative study was to identify some of the educational outcomes that students realize through participation in an SL course. This study focused on connecting SL pedagogy to specific evaluative criteria necessary for the accreditation of educational programs, other professional standards, and clinical performance competencies. She argued that SL experiences should encourage students to focus on making practical contributions beyond their professional role and expanding their perception and understanding of health and illness, particularly for members of underserved populations. In support of Reynolds' ideas about SL and professional education, the previously cited study by O'Meara and Niehaus (2009) has relevant findings. They report that $89 \%$ of faculty who do SL do it as a strategy for students to learn disciplinary knowledge and skills.

The three theoretical frames introduced above are compatible, yet differ in their ways of thinking about students, interacting with students, and developing courses and learning objectives. No inventory exists to look at the theoretical frames of faculty, particularly in regard to the three theoretical frames explored in the previous section. However, when considering progressive, critical, and professional theoretical frames and how they relate to ISL, multiple applications from each perspective can be identified since each frame relates to one or more of the ultimate goals of SL as identified by Kahne and Westheimer (1996). Based on the literature above, it may be appropriate to think that faculty will tend to lean in one of these three directions in terms of their theoretical framework for teaching. For example, progressivists would lean toward SL for its potential to provide opportunities for students to actively experience real life situations where group problem-solving is critical. The potential for SL to provide experiences that highlight the importance of democracy and allow for student empowerment and autonomy also would be valued by progressivists. Additionally, SL activities would appeal to progressivists because they are typically student-centered and include group discussion that connects the activity to moral and social development and the personalized construction of meaning.

Critical pedagogues would be intrigued by SL for its potential to create learning situations where students are transformed through active participation in opportunities to address current social justice issues and needs. Through these experiences, students might become socially alert and aware citizens who criticize the status quo. Critical pedagogues would also be drawn to SL because students and teachers typically work together collaboratively on the same level.

Finally, professional theorists would be attracted to SL because these opportunities put students in situations where they can develop competence and practice skills they have learned in the classroom. The professional theorists are pragmatic in their approach to teaching and learning. Therefore SL might be seen as a way to meet educational accreditation criteria linked to professional behaviors and attributes. SL would be useful to professional theorists as a way to link the classroom to future employment and work situations. 
Data collection procedures were approved by the University of Rhode Island's Institutional Review Board and included an informed consent procedure. Data collection was piloted prior to implementation. Both the informed consent and pilot procedures are detailed below.

\section{Faculty Survey}

Data for this study were collected through a four-part survey: 1) Demographics, 2) Teaching Style, 3) Theoretical Frame, and 4) ISL experience. This tool was formatted to accommodate on-line responding. Demographic data sought from subjects included age, gender, entry level physical therapy degree, the number of years as a physical therapist, faculty position, total number of years of teaching in physical therapy programs, and primary area of clinical interest. Teaching style data were collected with the Teaching Style Survey (Grasha \& Riechmann-Hruska, 1996). As previously described, this survey consists of 40 Likert items and produces scores in five teaching style types: Expert, Formal Authority, Personal Model, Facilitator, and Delegator. Further manipulation of these data categorizes subjects into one of four teaching style clusters: Cluster 1: Expert/Formal Authority, Cluster 2: Personal Model/Expert/Formal Authority, Cluster 3: Facilitator/ Personal Model/Expert, or Cluster 4: Delegator/Facilitator/Expert.

The theoretical frame data were collected through a researcher-developed 30 item Likert instrument that categorized subjects into one of three theoretical frame types: 1) Progressive, 2) Critical, or 3) Professional. This tool was developed to elicit responses that contrast progressive theory, critical pedagogy, and professional theory. Three additional items were included to explore the respondents' familiarity with the three theorists (Dewey, Freire, Reynolds) most closely associated with each of the theoretical frames.

Finally, subjects were asked to identify themselves as either having ISL experience (Y-ISL) or having no ISL experience (N-ISL). For the former group, data on preparation and reflection in their ISL work were also gathered.

\section{Survey Pilot}

Eight subjects provided pilot data. In order not to use potential subjects for the study, fellow doctoral candidates who teach in secondary education were asked to complete the survey as if they were teaching in a physical therapy program. Pilot subjects provided feedback regarding the length of the survey, ease of completion, clarity of items, and other logistical issues. Three revisions were made based on pilot feedback: expected time for completion was noted as 15 to 20 minutes, a typographical error was corrected, and the order of the survey items was adjusted so the Teaching Style survey appeared before the Theoretical Framework survey. This change in order was recommended because pilot feedback indicated that the Teaching Style Type (TST) section came across as less probing and sensitive than the items in the Theoretical Frame Type (TFT) section. The final survey is presented in Appendix A.

\section{Methods}

With the refined data collection tool, a sample of physical therapy program faculty members from across the country was sought. The physical therapy professional organization, the American Physical Therapy Association (APTA), was considered a viable avenue to recruit subjects. Specifically, the survey was offered to physical therapists through the listserves of the APTA's Education Section (personal contact, listserve manager at www.aptaeducation.org) and the APTA's Health, Policy and Administration Section's Cross Cultural and International Special Interest Group listserve (personal contact, listserve manager at jahartman@wisc.edu). The Faculty Survey was sent electronically, via a link to SurveyMonkey to all 566 and 250 members of these listserves, respectively. Recipients of the survey were asked to share the link with fellow faculty members not on either listserve. An informed consent statement was provided on the first page of the online survey. It was stated that consent was presumed if a person went on to complete the survey.

Using a convenience sample has many drawbacks. Purposive samples can leave out important members of a population. In this study, subject selection via professional organization listserves specifically eliminated physical therapy faculty who were either not members of the APTA, or are APTA members but are not members of the respective suborganizations, or are members of these subgroups, but do not participate in the list serves. It is unclear if, or how, subjects in this study differed from the broader population of physical therapy faculty. Based on the research topic and questions, however, identifying subjects via the two listserves was considered an acceptable way to gather data for this study.

Two other elements were important to the data collection. First, most if not all of the potential subjects were expected to be familiar with the SurveyMonkey ${ }^{\mathrm{TM}}$ online technology, as it has been used in the past on the targeted listserves for collecting research data. Although it is not required for membership in the educational listserve, a great majority of listserve members are presumed to be faculty. Since potential subjects were most likely to be working in academic settings with an academic calendar, the timing of the survey administration was matched as much as possible to a slow time in most academic calendars. Hence, data collection began on May 20, 2010 and was closed on June 21, 2010. 
In summary, the inclusion criteria for subject selection were:

- University faculty in a physical therapy program in the United States

- Member of either the a) Education Section of the American Physical Therapy Association listserve, b) Cross Cultural and International Special Interest Group of the American Physical Therapy Association listserve or c) a University faculty in a physical therapy program in the United States affiliated in some way with a member of the two listserves.

\section{Data Collection and Organization}

Two hundred sixty-six subjects responded to the listserve invitations to participate in the study. Thirty-seven subjects were immediately eliminated from the data pool because they only completed the demographic section of the survey and did not complete either the Teaching Style Type items or the Theoretical Frame Type items. An additional 24 surveys could not be used in the primary analysis because the subjects completed only the TST and not the TFT items. Ultimately, 205 survey responses were available for data analysis. This is about a $25 \%$ response rate from the potential sample of 816.

Collected data for each subject included demographics, Teaching Style Type (TST), Theoretical Frame Type (TFT), and self-reported ISL participation. The data collected through SurveyMonkey ${ }^{\mathrm{TM}}$ were downloaded into Excel 2007® then entered into IBM SPSS Version $19 \circledast$ for statistical analysis. The raw demographic data did not require manipulation prior to analysis. In contrast, the TST and TFT raw data both required manipulation before it could be used to address the research questions. These manipulations are described below.

\section{Teaching Style Types}

Each subject's responses to the TST items were entered into a scoring link for the Grasha and Reichmann tool http://www. longleaf.net/teachingstyle.html. This online tool tallied survey raw scores into teaching style information on the five teaching style types: Expert, Formal Authority, Personal Model, Facilitator, and Delegator. In addition to the raw numerical score, each raw score was identified as "high," "moderate," or "low" on the associated type. This latter piece of information was critically important because the raw scores on the different teaching style types are not on the same scale; a raw score of 3 on one type is not necessarily comparable to a raw score of 3 on another type. To address this lack of standardization across types, a TST Weighting Table (Appendix B) was developed. This table was used to determine each subject's TST by examining the relative strength of the raw scores in comparison to each other. The top two or three highest weighted types were noted for each subject. Only ratings of "high" and "moderate" were used.

The following example illustrates this procedure: consider a subject with the following raw scores: Expert $=3.375$, Formal Authority $=3.375$, Personal Model $=3.5$, Facilitator $=3.625$, and Delegator $=3.25$. According to the TST Weighting Table, the subject would be categorized as "moderate" for Expert, "high" for Formal Authority, "high" for Personal Model, "moderate" for Facilitator, and "high" for Delegator. Even though the subject has a Facilitator raw score that is higher than the Personal Model raw score (3.625 versus 3.5), because of the weighting of the raw scores, Personal Model is categorized as "high" and Facilitator is only "moderate." Additionally, even though the Expert raw score for this hypothetical subject is the same as the Formal Authority raw score (both equal 3.375), the Expert score is "moderate" while the Formal Authority score is "high." Therefore, this subject's combination of type rankings would result in placement in Cluster 2: Personal Model /Formal Authority/Delegator.

Once the highest TSTs and final cluster determination were determined for each subject, clustering was carried out per Grasha and Reichmann's procedures. Initially, the four cluster types most typical of college faculty as defined by Grasha and Reichmann were considered. It became evident, however, that the present data conformed to only one of the Grasha and Reichmann clusters, that being Expert/Formal Authority. Therefore, a phenomenological approach was used to group and sort responses based on predominant themes in the data (Bogdan, \& Biklen, 2003), Cluster 1 matched the Grasha and Reichmann clusters; however, four distinct new clusters emerged. Notably, PT faculty were much less likely than college faculty as a whole to have Expert, Formal Authority or Delegator as one of their highest teaching types. Going forward, these new clusters will be referred to as Physical Therapy Faculty Teaching Style Type (PT-TST) Clusters. Table 2 compares the Grasha and Reichmann TSTs to the newly developed physical therapy faculty clusters. Descriptions of the five physical therapy faculty teaching style types are given in Appendix C. 
Table 2 Grasha and Reichmann TST vs PT TST

\begin{tabular}{|c|c|c|c|}
\hline \multicolumn{2}{|c|}{$\begin{array}{l}\text { Grasha and Reichmann } \\
\text { Teaching Style Type }\end{array}$} & \multicolumn{2}{|c|}{$\begin{array}{l}\text { Physical Therapy Faculty Teaching } \\
\text { Style Type }\end{array}$} \\
\hline Cluster & $\begin{array}{l}\text { Experf TFormal } \\
\text { Authority }\end{array}$ & Cluster & Expert / Formal Authority \\
\hline $\begin{array}{l}\text { Cluster } \\
2\end{array}$ & $\begin{array}{l}\text { Personal Model } \\
\text { / Expert / Formal } \\
\text { Authority }\end{array}$ & $\begin{array}{l}\text { Cluster } \\
2\end{array}$ & $\begin{array}{l}\text { Personal Model / Formal } \\
\text { Authority / Delegator }\end{array}$ \\
\hline $\begin{array}{l}\text { Cluster } \\
3\end{array}$ & $\begin{array}{l}\text { Facilitator / } \\
\text { Personal Model / } \\
\text { Expert }\end{array}$ & $\begin{array}{l}\text { Cluster } \\
3\end{array}$ & $\begin{array}{l}\text { Formal Authority / } \\
\text { Delegator }\end{array}$ \\
\hline $\begin{array}{l}\text { Cluster } \\
4\end{array}$ & $\begin{array}{l}\text { Delegator / } \\
\text { Facilitator / Expert }\end{array}$ & $\begin{array}{l}\text { Cluster } \\
4 \\
\text { Cluster } \\
5\end{array}$ & $\begin{array}{l}\text { Formal Authority / } \\
\text { Facilitator / Delegator } \\
\text { Delegator / Facilitator }\end{array}$ \\
\hline
\end{tabular}

Theoretical Frame Type

Theoretical Frame Types were derived by tallying and averaging the raw scores on progressive, critical, and professional items of the TFT section of the faculty survey. One item (\#30) required reverse scoring so that its valence would be consistent with the remaining items. The highest average score was used to assign a TFT to each subject. In nearly all cases (96\%) a clear high score, and therefore TFT, was evident. Nine tied scores existed, and data were coded as such.

The manipulated TST and TFT data were entered into the IBM SPSS Version $19 \circledast$ data sheet, as were data on the final two variables: subject familiarity with key theorists and their participation (yes or no) in ISL. Three data sheets were developed: 1) an Initial Data Sheet which included subjects who provided any data (n=266), 2) a TST Only Data Sheet which included data from subjects who provided complete data on everything except the TFT $(n=229)$, and 3) a Complete Data Sheet which included data from subjects who provided data on all study variables $(n=205)$. The Complete Data Sheet was used for data entry. 


\section{Data Analysis}

The data from 205 subjects were used for analysis. Of those, 47 (23\%) reported having participated in international service-learning with groups of students and are referred to as the Y-ILS group; 158 (77\%) reported that they had not participated in international service-learning with groups of students and are referred to as the N-ISL group. The only unexpected finding within the demographic data was that more than one-quarter of the subjects ( $\mathrm{n}=55,27 \%$ ) did not report their age.

\section{Descriptive Statistics}

First, descriptive statistics were calculated for all of the data and are presented in Tables 3 through 8 . Inferential statistics were utilized to determine if there were significant differences between the Y-ISL and N-ISL groups for the demographic variables. Independent t-test was used with the continuous data, specifically for the age, years as a PT, and years teaching data. Pearson chi-square was used with the nominal data, which included gender, entry level degree, faculty position, and primary area of interest. For each of the t-tests, equal variance was assumed using Levene's Test for Equality of Variance.

Table 3 shows that no differences were found between the Y-ISL and the N-ISL groups for gender or years teaching. Significant differences were found between the Y-ISL and the N-ISL groups for age and years as a physical therapist.

Table 3 Descriptive Statistics for Demographic Variables

\begin{tabular}{|c|c|c|c|c|}
\hline \multicolumn{5}{|c|}{ Demographics } \\
\hline Item & \begin{tabular}{c} 
APTA \\
Data \\
www.apta. \\
\multicolumn{1}{c}{ ra }
\end{tabular} & $\begin{array}{c}\text { Total Sample } n \\
(\%) \\
(n=205)\end{array}$ & $\begin{array}{c}\text { N-ISL n (\%) } \\
(n=158)\end{array}$ & $\begin{array}{c}\text { Y-ISL n (\%) } \\
(n=47)\end{array}$ \\
\hline \multirow[t]{5}{*}{ Gender } & $\begin{array}{c}\text { Female } \\
\text { (68.1\%) } \\
\text { Male } \\
(31.9 \%)\end{array}$ & $\begin{array}{c}\text { Female } 154 \\
(77.4 \%) \\
\text { Male } 45 \\
(22.6 \%)\end{array}$ & $\begin{array}{c}\text { Female } 115 \\
(74.7 \%) \\
\text { Male } 39 \\
(25.3 \%)\end{array}$ & $\begin{array}{c}\text { Female } 39 \\
(86.7 \%) \\
\text { Male 6 } \\
(13.3 \%)\end{array}$ \\
\hline & & $\mathrm{n}=199$ & $n=154$ & $n=45$ \\
\hline & & Missing 6 & Missing 4 & Missing 2 \\
\hline & & Total 205 & Total 158 & Total 47 \\
\hline & & & \multicolumn{2}{|c|}{ Pearson chi-square $=.091 \mathrm{NS}$} \\
\hline \multirow[t]{5}{*}{$\begin{array}{l}\text { Age } \\
\text { (years) }\end{array}$} & $\begin{array}{l}\text { Mean } \\
42.9\end{array}$ & $\begin{array}{c}\text { Mean = 49.92 } \\
(+/-8.03)\end{array}$ & $\begin{array}{l}\text { Mean = } \\
48.98\end{array}$ & $\begin{array}{c}\text { Mean = 53.12 } \\
(+/-8.49)\end{array}$ \\
\hline & & $n=150$ & $\frac{n=117}{n=17}$ & $n=32$ \\
\hline & & Missing 55 & Missing 40 & Missing 15 \\
\hline & & Total 205 & Total 158 & Total 47 \\
\hline & & & \multicolumn{2}{|c|}{$t=2.610, p=.010^{*}$} \\
\hline \multirow[t]{5}{*}{$\begin{array}{l}\text { Years as } \\
\text { PT }\end{array}$} & $\begin{array}{l}\text { Mean } \\
17.4\end{array}$ & $\begin{array}{c}\text { Mean }=26.23 \\
(+/-9.45)\end{array}$ & $\begin{array}{l}\text { Mean = } \\
25.36 \\
(+1-920)\end{array}$ & $\begin{array}{c}\text { Mean }=29.02 \\
(+/-9.86)\end{array}$ \\
\hline & & $\mathrm{n}=197$ & $\mathrm{n}=152$ & $n=45$ \\
\hline & & Missing 8 & Missing 6 & Missing 2 \\
\hline & & Total 205 & Total 158 & Total 47 \\
\hline & & & \multicolumn{2}{|c|}{$t=2.194, p=.029^{*}$} \\
\hline \multirow[t]{5}{*}{ Years } & & $\begin{array}{c}\text { Mean = } 14.46 \\
(+/-8.58)\end{array}$ & $\begin{array}{c}\text { Mean }= \\
13.98 \\
(+/-8.08)\end{array}$ & $\begin{array}{c}\text { Mean = } 16.02 \\
(+/-10.06)\end{array}$ \\
\hline & & $n=203$ & $n=157$ & $n=46$ \\
\hline & & Missing 2 & Missing 1 & Missing 1 \\
\hline & & Total 205 & Total 158 & Total 47 \\
\hline & & & \multicolumn{2}{|c|}{$t=1.435, p=.153 \mathrm{NS}$} \\
\hline
\end{tabular}

$* p<.05$, NS $=$ Not Significant

It was expected that Age and Years as a Physical Therapist were positively correlated and were not independent factors. A Pearson correlation analysis confirmed this $(n=148, r=.727)$.

Next, the descriptive statistics and Pearson chi-square analysis related to subject entry level degree were calculated and are represented in Table 4. A majority of subjects completed their initial physical therapy training in bachelor degree programs. There is no significant relationship between entry level degrees and ISL participation. 
Table 4 Descriptive Statistics for Professional Background Variable: Entry Level Degree

\begin{tabular}{|c|c|c|c|}
\hline \multirow{3}{*}{ Item } & \multicolumn{2}{|c|}{$\begin{array}{c}\text { Entry Level Degree } \\
\text { Sample }\end{array}$} & \multirow{2}{*}{$\begin{array}{l}\text { Y-ISL } n(\%) \\
(n=47)\end{array}$} \\
\hline & $\begin{array}{l}\text { Sample } n(\%) \\
(n=205)\end{array}$ & $\begin{array}{l}N-15 \operatorname{Ln}(\%) \\
(n=158)\end{array}$ & \\
\hline & $(133$ & $\frac{(11-100}{101}$ & 32 \\
\hline Masters & $\frac{(66.2 \%)}{30}$ & $(65.2 \%)$ & $(69.6 \%)$ \\
\hline & $(14.9 \%)$ & (14.8\%) & $(15.2 \%)$ \\
\hline MPT & 19 & 16 & 3 \\
\hline DPT & $(9.5 \%)$ & $\frac{0.3 \%)}{15}$ & $\frac{5.5 \%)}{4}$ \\
\hline$n$ & $\left(\frac{9.5 \%)}{201}\right.$ & $(9.7 \%)$ & $(8.7 \%)$ \\
\hline Missing & 4 & 3 & 1 \\
\hline $\begin{array}{l}\text { Data } \\
\text { Total }\end{array}$ & 205 & 158 & 47 \\
\hline & & Pearson ch & $=.877 \mathrm{NS}$ \\
\hline
\end{tabular}

NS $=$ Not Significant

Similarly, Table 5 represents that there is no significant relationship between faculty position and ISL participation based on descriptive statistics and Pearson chi-square analysis.

Table 5 Descriptive Statistics for Professional Background Variable: Faculty Position

\begin{tabular}{|c|c|c|c|}
\hline \multicolumn{4}{|c|}{ Faculty Position } \\
\hline riem & $(n=205)$ & $\begin{array}{c}(n=158) \\
(n+1)\end{array}$ & $\begin{array}{c}\text { Y-ISL } n(\%) \\
(n=47)\end{array}$ \\
\hline Lecturer & 11 & 8 & 3 \\
\hline Clinical Assistant & $\frac{(5.4 \%)}{34}$ & $\frac{(5.1 \%)}{24}$ & $(6.4 \%)$ \\
\hline Professor & $(16.7 \%)$ & $(15.4 \%)$ & $(21.3 \%)$ \\
\hline $\begin{array}{l}\text { Associate } \\
\text { Professor }\end{array}$ & $\begin{array}{c}68 \\
(335 \%)\end{array}$ & 31 & 17 \\
\hline Professor & 53 & 42 & 11 \\
\hline $\begin{array}{l}\text { Other } \\
\text { (Assistant } \\
\text { Professor) }\end{array}$ & $\begin{array}{c}(26.1 \%) \\
37 \\
(18.2 \%)\end{array}$ & $\begin{array}{c}(26.9 \%) \\
31 \\
(19.9 \%)\end{array}$ & $\begin{array}{c}(23.4 \%) \\
6 \\
(12.8 \%)\end{array}$ \\
\hline$n$ & 203 & 156 & 47 \\
\hline Missing Data & 2 & 2 & 0 \\
\hline Total & 205 & 158 & 47 \\
\hline & & Pearson chi- & $\mathrm{e}=.707 \mathrm{NS}$ \\
\hline
\end{tabular}

NS $=$ Not Significant

Descriptive statistic and Pearson chi-square analyses were carried out to explore the relationship between primary area of clinical interest and ISL participation. No significant relationship was identified (Table 6). 
Table 6 Descriptive Statistics for Professional Background Variable: Primary Area of Clinical Interest

\begin{tabular}{|c|c|c|c|}
\hline \multicolumn{4}{|c|}{ Primary Area of Interest } \\
\hline Ttem & $\begin{array}{c}\text { Sample } n(\%) \\
(n=205)\end{array}$ & $\begin{array}{c}\text { N-ISL n (\%) } \\
(n=158)\end{array}$ & $\begin{array}{c}\text { Y-ISL n (\%) } \\
(n=47)\end{array}$ \\
\hline Basic Science & 17 & 14 & 3 \\
\hline Orthopedic & $(8.3 \%)$ & $\frac{(8.9 \%)}{29}$ & $(6.5 \%)$ \\
\hline Pediatric & $(16.1 \%)$ & $(18.4 \%)$ & $(8.7 \%)$ \\
\hline reciamic & $(9.3 \%)$ & $(7.6 \%)$ & $(152 \%)$ \\
\hline Geriatrics & $(6.8 \%)$ & $\begin{array}{l}(1.010) \\
(7.0 \%)\end{array}$ & $\begin{array}{l}3 \\
(6.5 \%)\end{array}$ \\
\hline & $\begin{array}{c}10 \\
(4.9 \%)\end{array}$ & $\begin{array}{c}8 \\
(5.1 \%)\end{array}$ & $(4.4 \%)$ \\
\hline Neurological & $\begin{array}{c}31 \\
(15.1 \%)\end{array}$ & $\begin{array}{c}24 \\
(15.2 \%)\end{array}$ & $(15.2 \%)$ \\
\hline $\begin{array}{l}\text { Professional } \\
\text { Issuęs }\end{array}$ & $\begin{array}{c}22 \\
(10.7 \%)\end{array}$ & $(10.1 \%)$ & $(13.0 \%)$ \\
\hline $\begin{array}{l}\text { Clinical } \\
\text { Education }\end{array}$ & $\begin{array}{c}45 \\
(22.0 \%)\end{array}$ & $\begin{array}{l}34 \\
(215 \%)\end{array}$ & 111 \\
\hline Research & $\begin{array}{l}13 \\
(6.3 \%)\end{array}$ & $(6.3 \%)$ & $\begin{array}{c}3 \\
(6.5 \%)\end{array}$ \\
\hline$n$ & 204 & 158 & 46 \\
\hline Missing Data & 1 & 0 & 1 \\
\hline Total & 205 & 158 & 47 \\
\hline & & Pearson $\mathrm{ch}$ & $=.765 \mathrm{NS}$ \\
\hline
\end{tabular}

NS $=$ Not Significant

A summary the descriptive data for teaching style clusters for the whole sample, N-ISL, and Y-ISL groups is shown in Table 7.

Table 7 Descriptive Statistics for Teaching Style Type Clusters

\begin{tabular}{|l|c|c|c|}
\hline \multicolumn{4}{|c|}{ Physical Therapy Faculty Teaching Style Type (TST) Clusters } \\
\hline Item & $\begin{array}{c}\text { Sample n (\%) } \\
(\mathrm{n}=205)\end{array}$ & $\begin{array}{c}\text { N-ISL }(\%) \\
(\mathrm{n}=158)\end{array}$ & $\begin{array}{c}\text { Y-ISL n (\%) } \\
(\mathrm{n}=47)\end{array}$ \\
\hline $\begin{array}{l}\text { Cluster 1 } \\
\text { Expert / Formal Authority }\end{array}$ & $(9.3 \%)$ & $(8.9 \%)$ & $(10.6 \%)$ \\
\hline $\begin{array}{l}\text { Cluster 2 } \\
\text { Personal Model / Formal } \\
\text { Authority / Delegator }\end{array}$ & 107 & 87 & 20 \\
\hline $\begin{array}{l}\text { Cluster 3 } \\
\text { Formal Authority / } \\
\text { Delegator }\end{array}$ & $(51.2 \%)$ & $(55.1 \%)$ & $(42.6 \%)$ \\
\hline $\begin{array}{l}\text { Cluster 4 } \\
\text { Formal Authority / } \\
\text { Facilitator / Delegator }\end{array}$ & $(11.7 \%)$ & $(10.8 \%)$ & $(14.9 \%)$ \\
\hline $\begin{array}{l}\text { Cluster 5 Delegator / } \\
\text { Facilitator }\end{array}$ & 42 & 28 & 14 \\
\hline $\mathrm{n}$ & $(6.3 \%)$ & $(17.7 \%)$ & $(29.8 \%)$ \\
\hline
\end{tabular}


Table 8 provides a summary the descriptive data for theoretical frame types for the whole sample, N-ISL, and Y-ISL groups.

Table 8 Descriptive Statistics for Theoretical Frame Type

\begin{tabular}{|l|c|c|c|}
\hline \multirow{2}{*}{ Them } & $\begin{array}{c}\text { Theoretical Frame Type (TFI) } \\
\text { Sample } \\
(\%) \\
(n=205)\end{array}$ & $\begin{array}{c}\text { N-ISL } n(\%) \\
(n=158)\end{array}$ & $\begin{array}{c}\text { Y-ISL } n(\%) \\
(n=47)\end{array}$ \\
\hline Progressive & 80 & 60 & 20 \\
& $(39.0 \%)$ & $(38.0 \%)$ & $(42.6 \%)$ \\
\hline Critical & 5 & 1 & 4 \\
\hline Professional & $(2.4 \%)$ & $(0.6 \%)$ & $(8.5 \%)$ \\
\hline Tie Progressive/ & $(54.2 \%)$ & $(55.7 \%)$ & $(48.9 \%)$ \\
Professional & 8 & 8 & 0 \\
\hline Tie Progressive/Critical & $(3.9 \%)$ & $(5.1 \%)$ & $(0 \%)$ \\
\hline $\mathrm{n}$ & $(0.5 \%)$ & $(0.6 \%)$ & 0 \\
\hline
\end{tabular}

To explore the groups' familiarity with key educational theorists, average familiarity scores were calculated for the whole sample and for Y-ISL and N-ISL groups. Independent sample t-test analyses were then carried out. For each of the t-tests, equal variance was assumed using Levene's Test for Equality of Variance. Average reported familiarity scores were based on a scale of 1 (Not Familiar) to 10 (Very Familiar).

When looking at the sample as a whole, significant differences were found between the Y-ISL and the N-ISL groups for level of familiarity with Dewey, Freire, and Reynolds. It seemed misleading to use the whole subject group since so many subjects scored themselves as 1 or "Not Familiar." These "Not Familiar" data for Dewey, Freire and Reynolds were $85(41 \%), 154$ (75\%) and 155 (76\%), respectively. Therefore a second calculation with the data manipulated to look only at subjects reporting anything other than "Not Familiar" was carried out. That analysis resulted in significantly different levels of familiarity between Y-ISL and N-ISL groups only for Reynolds. Table 9 provides a summary of these data.

Table 9 Descriptive Statistics for Familiarity with Key Theorists

\begin{tabular}{|c|c|c|c|}
\hline & Fa & th Key Th & \\
\hline$\frac{\text { them }}{\text { Dewey }}$ & $\begin{array}{l}\text { Sample } \\
(n=205)\end{array}$ & $\begin{array}{c}N-S L \\
(n=158)\end{array}$ & $\begin{array}{l}Y-1 S L \\
(n=47)\end{array}$ \\
\hline & 4.37 & 4.12 & 5.17 \\
\hline & & & $48^{*}$ \\
\hline & 851 & cts repo & iliarity" \\
\hline & & reportir & iliar" \\
\hline & $(n=120)$ & $(n=84)$ & $(n=36)$ \\
\hline & 6.48 & 6.50 & 6.44 \\
\hline & & & NS \\
\hline Freire & $(n=205)$ & $(n=158)$ & $(n=47)$ \\
\hline & 2.47 & 2.22 & 3.26 \\
\hline & & & $22^{*}$ \\
\hline & 154 & cts repc & hiliarity" \\
\hline & & s reportir & iliar" \\
\hline & $(n=51)$ & $(n=32)$ & $(n=19)$ \\
\hline & 6.61 & 6.63 & 6.58 \\
\hline & & & NS \\
\hline Reynolds & $(n=205)$ & $(n=158)$ & $(n=47)$ \\
\hline & 2.3 & 2.0 & 3.26 \\
\hline & & & $54^{* *}$ \\
\hline & 155 & cts repc & niliarity" \\
\hline & & s reportir & niliar' \\
\hline & $(n=50)$ & $(n=34)$ & $(n=16)$ \\
\hline & 6.08 & 5.35 & 7.63 \\
\hline & & & $58^{* *}$ \\
\hline
\end{tabular}

${ }^{*} p<.05,{ }^{* *} p<.01$, NS $=$ Not Significant

\section{Chi-Square}

The data were analyzed to determine if there was a relationship between the subject's involvement in SL (Y-ILS / N-ILS) and their teaching styles (TST), and between the SL variable and their theoretical frame (TFT). Chi-square was the appropriate statistical tool since the data were nominal, there were more than two variables, and it can be used to 
identify relationships between the dependent variable (DV) and independent variables (IV) (Harlow, 2000; Protsman \& Carlson, 2008; Weiss, 2005). The chi-square test was used to look at the difference between observed frequencies and the expectation that the date would be evenly distributed among all levels of the IV. The contingency table and the associated significance test (Table 10) show that there is not a significant relationship between TST and ISL.

Table 10 Chi-Square Analysis Comparing ISL Variable and Teaching Style

\begin{tabular}{|c|c|c|c|c|c|c|}
\hline & $\begin{array}{l}\text { Cluster } \\
1: \\
\text { Expert / } \\
\text { Formal }\end{array}$ & $\begin{array}{l}\text { Cluster } \\
\text { 2: } \\
\text { Personal } \\
\text { Model / } \\
\text { Formal } \\
\text { Authority }\end{array}$ & $\begin{array}{l}\text { Cluster } \\
\text { 3: } \\
\text { Formal } \\
\text { Authority } \\
\text { / }\end{array}$ & $\begin{array}{l}\text { Cluster 4: } \\
\text { Formal } \\
\text { Authority } \\
\text { / }\end{array}$ & $\begin{array}{l}\text { Cluster } \\
\text { 5: }\end{array}$ & \\
\hline N-ISL & $\begin{array}{l}E=31.6 \\
0=13\end{array}$ & $\begin{array}{l}E=31.6 \\
0=88\end{array}$ & $\begin{array}{l}E=31.6 \\
0=17\end{array}$ & $\begin{array}{l}E=31.6 \\
O=28\end{array}$ & $\begin{array}{l}E=31.6 \\
O=12\end{array}$ & 158 \\
\hline Y-ISL & $\begin{array}{l}E=9.4 \\
O=5\end{array}$ & $\begin{array}{l}E=9.4 \\
0=? 0\end{array}$ & $\begin{array}{l}E=9.4 \\
0=7\end{array}$ & $\begin{array}{l}E=9.4 \\
O=14\end{array}$ & $E=9.4$ & 47 \\
\hline $\begin{array}{c}n \\
\text { Total } \\
n= \\
205\end{array}$ & $-\frac{1}{18}$ & 108 & -24 & $\begin{array}{r}-44 \\
42\end{array}$ & -13 & $\begin{array}{l}\text { Chi- } \\
\text { square } \\
= \\
6.020 \\
\text { NS }\end{array}$ \\
\hline
\end{tabular}

NS = Not Significant

A significant relationship exists between TFT and ISL. The contingency table and the associated significance are presented in Table 11.

Table 11 Chi-Square Analysis Comparing ISL Variable and Theoretical Frame

\begin{tabular}{|c|c|c|c|c|}
\hline & $\begin{array}{c}\text { Progressive } \\
\text { Theory }\end{array}$ & $\begin{array}{l}\text { Critical } \\
\text { Pedagogy } \\
\text { Theory }\end{array}$ & $\begin{array}{c}\text { Professional } \\
\text { Theory }\end{array}$ & \\
\hline N-ISL & $\begin{array}{l}E=49.7 \\
0=60\end{array}$ & $E=49.7$ & $\begin{array}{l}E=49.7 \\
O=88\end{array}$ & 149 \\
\hline Y-ISL & $\begin{array}{l}E=14.3 \\
O=20\end{array}$ & $\begin{array}{l}E=14.3 \\
O=4\end{array}$ & $\begin{array}{l}E=14.3 \\
O=23\end{array}$ & 47 \\
\hline $\begin{array}{c}\mathrm{n} \\
\text { Total } \\
\mathrm{n}= \\
196\end{array}$ & 80 & 5 & 111 & $\begin{array}{l}\text { Chi- } \\
\text { square: } \\
12.394^{*}\end{array}$ \\
\hline
\end{tabular}

$* p<.05$

Logistic Regression

Finally, logistic regression was used to analyze the relationship between the SL bimodal variable (Y-ISL and N-ISL) and the Physical Therapy Faculty Teaching Style Type (PT-TST) and Theoretical Frame Type (TFT). Recall the PT-TST has five potential values, and the TFT variable has three potential values. Factors were entered in the regression in three blocks.

Demographics were added in the first block because it was felt that while they might be related, that relationship would be smaller. The decision to enter these two particular demographic factors was based on the research questions, results of the descriptive statistical analysis, chi-square analysis, and Pearson correlation results. Although gender was not found to be significant it was used as a grounding factor for the regression. A factor for age centered around the mean was also entered in the first block. Age and years as a physical therapist were found to be significant but highly correlated. Age was chosen over years as a physical therapist since it was felt that age may be a more representative of why faculty members choose to participate in ISL.

In the second block TST clusters were entered individually. TFT was added as the third block because it is also one of the primary factors being investigated to answer the research question. The contribution of TST and TFT factors to predict participation in ISL were of the greatest interest in the study and were therefore entered in later blocks. 
Table 12 represents the factors added in each block and the associated beta values and significance levels. The progressive increase in $\mathrm{R}^{2}$ values demonstrate the amount of variance accounted for by the added variables. The regression model does not significantly predict participation in ISL.

Table 12 Logistic Regression

\begin{tabular}{|c|c|c|c|c|}
\hline & & B & SE & Sig. \\
\hline & $\begin{array}{l}\text { Constant } \\
\text { (Female, Age 49.92, } \\
\text { Cluster 2, Personal } \\
\text { Model / Formal Authority } \\
\text { / Delegator, and } \\
\text { Professional) }\end{array}$ & .248 & .310 & .000 \\
\hline \multirow{3}{*}{$\begin{array}{l}\text { Block } \\
1\end{array}$} & Male & .437 & .501 & .098 \\
\hline & Age & 1.054 & .027 & .053 \\
\hline & & & & $R^{2}=.066$ \\
\hline \multirow[t]{5}{*}{$\begin{array}{l}\text { Block } \\
2\end{array}$} & $\begin{array}{l}\text { Cluster } 1 \\
\text { Expert / Formal Authority }\end{array}$ & 1.580 & 597 & .443 \\
\hline & $\begin{array}{l}\text { Cluster } 3 \\
\text { Formal Authority / } \\
\text { Delegator }\end{array}$ & 1.839 & .529 & $\begin{array}{l}.249 \\
\text { NS }\end{array}$ \\
\hline & $\begin{array}{l}\text { Cluster } 4 \\
\text { Formal Authority / } \\
\text { Facilitator / Delegator }\end{array}$ & 1.497 & .451 & .371 \\
\hline & $\begin{array}{l}\text { Cluster } 5 \\
\text { Delegator / Facilitator }\end{array}$ & .352 & 1.103 & .345 \\
\hline & & \multicolumn{3}{|c|}{$\begin{aligned} R^{2} & =.099 \\
\Delta R^{2} & =.033\end{aligned}$} \\
\hline \multirow{2}{*}{$\begin{array}{l}\text { Block } \\
3\end{array}$} & $\begin{array}{l}\text { Critical } \\
\text { Progressive }\end{array}$ & $\begin{array}{l}12.049 \\
1.248\end{array}$ & $\begin{array}{l}1.223 \\
.371\end{array}$ & \\
\hline & & \multicolumn{3}{|c|}{$\begin{aligned} R^{2} & =.137 \\
\Delta R^{2} & =.038\end{aligned}$} \\
\hline
\end{tabular}

$* p<.05$, NS $=$ Not Significant 


\section{Discussion of Results}

There is no reason to expect that the trend of physical therapy programs adding ISL opportunities will end any time soon. In that context, these data provide important descriptive information and insight into physical therapy faculty, including those doing ISL. This information does not exist in the current literature and provides unique information relevant for physical therapy program directors, accrediting agencies, the American Physical Therapy Association (APTA), faculty, students, and professional special interest groups. An example of the latter is the APTA Cross Cultural and International Special Interest Group, which is an active and growing subsection of the Heath Policy and Administration Section of the APTA. The data can be used to inform policy development, strategic planning and decision making, curriculum development, and staffing and budget decisions.

\section{Research Question \# 1}

The data indicate that the answer to Research Question 1: Do ISL and non-ISL faculty differ on demographic variables? is that there are some meaningful differences between the groups. The two groups are different in terms of two strongly correlated factors: age and years of practice. The faculty who participate in ISL tend to be older and have more years of practice than their non-ISL counterparts. This has several implications. First, it may be that older faculty become dissatisfied with classroom teaching alone for achieving favorable student outcomes. Second, it may indicate that older faculty are willing to investigate and participate in ISL as a way to invigorate their own teaching and learning. Third, it may indicate that they have more flexibility and latitude to explore and develop ISL programs for students. Although tenure data were not included in this study, perhaps younger faculty on a tenure track feel there is too much risk associated with, and not enough available time to pursue the atypical, potentially time-consuming pedagogy of ISL. Finally, it may be that older faculty have more personal freedom to travel. If physical therapy programs value ISL, and would like to groom faculty in that direction, these data suggest that workloads and financial resources should be congruent with the time commitment needed to realize a vital ISL program. In addition, invested programs should support their commitment to ISL as an important part of the tenure process. This might include a clearly stated recognition of the value of ISL, provision of necessary resources, and acknowledgment of ISL participation as yet another component of the decision making process for tenure along with teaching, research, and service. These signs of support would help to ease concerns about how ISL leadership would be viewed by tenure review bodies and may increase the number of younger faculty who choose to be involved. Of course, if tenure review bodies do not value ISL, interested faculty may choose to limit their participation until after achieving tenure. Given the value of ISL (see Chisholm, 2003; Craft, 2002; Hartman \& Rola, 2000; Silcox \& Leek, 1997) and the profession's encouragement of this pedagogy, this delay would be unfortunate.

No meaningful differences were found between groups for gender, faculty position, or primary area of interest. The statistical tests failed to reject the null hypothesis in these analyses and accord differences to sampling error at an alpha of .05. Even though expected differences were not found, the findings raise interesting points about the diversity of faculty doing ISL.

Male and female faculty holding a range of academic positions, with differing entry-level educational experiences, and focusing on numerous clinical interests have all been involved in ISL. Indeed, making assumptions about faculty interest in ISL may not be helpful, since there does not appear to be one type of faculty member that finds ISL participation beneficial. This is an exciting finding which speaks to the robustness of ISL across highly varied themes. For example, it is not uncommon to hear groups of faculty discuss the characteristic differences between those who teach orthopedic treatment courses and those who teach neurological treatment courses. It is commonly felt that these faculty differ from each other in their style and in the way they think. It is interesting to speculate about how both characteristic groups might be equally suited to ISL. It is also intriguing to consider that both orthopedic and neurological faculty may find ISL beneficial for very different reasons. If ISL can be seen as a pedagogy that might unite traditionally diverse faculty, there is a unique opportunity for collaborative discussion and work. Additionally, there is potential to open the ISL discussion to all physical therapy faculty, perhaps drawing in faculty who may have viewed ISL as a nice 'extra,' but not for them because it is seen as being incompatible with teaching their specific physical therapy content.

\section{Research Question \#2}

Research question 2 asks What are the teaching styles and theoretical frames of faculty who carry out ISL in physical therapy education and those who do not? Are there differences between groups? It was expected that there would be divergence in theoretical frame types both among and between Y-ISL and N-ISL participant groups. It was expected that all faculty would employ some of each of the three frames, yet all would have an identifiable predominant TFT.

\section{Teaching Style Type}

Recall, the TST survey produced data related to five distinct teaching types: Expert, Formal Authority, Personal Model, Facilitator, and Delegator. These data were then combined into five physical therapy faculty specific teaching 
style type, or PT TST clusters: Expert/Formal Authority, Personal Model/Formal Authority/ Delegator, Formal Authority/ Delegator, Formal Authority/Facilitator/Delegator, Delegator/Facilitator. As mentioned previously, these physical therapy specific cluster types did not fit Grasha and Reichmann's four original faculty TST clusters. Grasha (1996) had many more faculty who fell into the Expert TST, and many fewer who were categorized with TSTs of Delegator or Facilitator. This interesting finding could be associated with several, probably intertwined considerations: changes in educational practice across the academy since 1996 when Grasha's tool was developed, differences in teaching practices between all faculty in higher education and faculty in physical therapy and other health professions, or differences in the innate characteristics of all faculty and physical therapy faculty.

In general, teaching practice in the last 15 years has moved away from the teacher expert / informer model to more collaborative ways of teaching and learning. While this has undoubtedly happened across the academy, it is likely to be a more prominent feature in the education of health care professionals because of its inherent, hands-on nature. Health professionals' education has always been characterized by hands-on, experiential teaching practices, active learning, and case study. Another difference that might explain the new clusters found in this study relates to student outcomes. In the last decade, notable emphasis has been put on identifying and measuring appropriate student outcomes across higher education. Again, this has been a routine part of health care profession education for decades, as student outcomes are intimately linked to educational accreditation standards. Worth further consideration is the idea that there could also be innate differences between all higher education faculty and physical therapy faculty. The career path to an academic faculty position may be different for these two groups. In contrast to most other fields, physical therapy faculty often enter academia directly from clinical settings with little formal teaching experience; however, they are very likely to have had experience teaching is less formal ways. For example, physical therapy faculty often come from a background of clinical practice where they most likely worked with patients as a member of a healthcare team. Inherent in the role of a physical therapist as clinician is teaching of patients and colleagues. Although expertise is required, the roles of both teacher and clinical practitioner necessitate collaborative partnerships and communication. Without physical therapy faculty teaching style data from the mid-90s, it is impossible to know which consideration (changes in all of higher education, differences between physical therapy faculty and other faculty, or inherent differences in physical therapist faculty) is most salient. It will be interesting to further explore teaching styles of physical therapy faculty to see if the clusters identified in this study are reproduced and if they are similar to other allied health educators and/or more traditional academic educators.

The subjects in this study tended to fall into Grasha and Reichmann's categories that emphasize role modeling, delegation of responsibilities, student autonomy, and expertise that is exemplified by high standards of performance and facilitation of hands-on active learning. Consistently, it is less common for physical therapy faculty to have a teaching style that relies on the transmission of information to students who wait to learn from them.

Acknowledging the new teaching style clusters identified in this study, the discussion will now address ways in which this information may be used. Since teaching style data for physical therapy educators have not been previously available, they may serve as a catalyst for a broad array of discussions. For example, these data can provide a common language for educators. Since PTs rarely come into academia positions with teaching backgrounds, they may not have a common language through which to describe and discuss their teaching. This can be particularly important for novice faculty who may initially flounder in the classroom as they attempt to maintain high academic standards while simultaneously engaging students on a more personal level. For example, a novice educator may feel they are a collaborative teacher, but find themselves with an Expert teaching style. Exploring that difference can lead to meaningful reflection of teaching process and rich discussions of educational philosophy.

While the exploration of how physical therapy faculty TST is related to student learning style is beyond the scope of this study, it would be beneficial to explore. In his book, Grasha (1996) devotes chapters to how faculty teaching style and student learning style are influenced by each other. Expert teachers are in tune with how to alter their teaching in response to student learning preferences. It is worth noting that there are many more learning style inventories than there are teaching style inventories. Perhaps this is due to teachers and faculty being much more interested in looking at student issues than looking inwardly at themselves.

\section{Theoretical Frame Type}

Similar to the TST data, the theoretical frame data are of interest for several reasons. Outside of this study, these data do not exist in physical therapy and it is unknown how many physical therapist educators are even aware of educational theories in the same way that they are aware of theories of specific treatment techniques.

Critical pedagogy and progressive ideas, although they may be valued by individual physical therapy faculty members, were not the most prominent theories to emerge. A majority of the subjects (54\%) identified most strongly with professional theory ideas. Most physical therapy programs struggle to get all of the required professional knowledge and skills into their curricula, so the ideas valued by progressive and critical pedagogues may take a back seat in physical therapist education. It is interesting to note, however, that even within those rigid constraints, 39\% identified most strongly with non-professional pedagogy views. CAPTE accreditation standards include criteria related to the ideas espoused by progressivists and criticalists; however, the ways in which these criteria are "lived" in physical therapy education is in its infancy. Programs struggle to integrate these criteria in ways that are meaningful and 
valuable for students. Consideration of the work of progressivists and criticalists could meaningfully contribute to these curricular processes.

When looking at the sample as a whole, subjects were most often categorized as having either a professional or progressive theoretical frame, yet familiarity with the writings of representative key theorists was quite limited. The number of faculty who reported that they had no familiarity (Dewey, 41\%; Freire, 75\%; and Reynolds $76 \%$ ) with the key theorists illustrates this clearly. Further analysis using the level of familiarity of only those subjects who had reported any score greater than "no familiarity" was completed. Most faculty were categorized as professional theorists, yet they were only minimally familiar with the work of Pamela Reynolds, who writes about professional education in physical therapy and the relevance of SL as a part of PT curriculum. Similarly, many of the subjects were categorized as having a progressivist frame. Progressive theory is a hallmark of Dewey's work. On the 1 to 10 familiarity scale, the sample was also only moderately familiar with his writing. In general, the sample was only minimally familiar with the writing of Freire, which is further reflected in the small number of faculty who were categorized as Critical TFT. These data suggest that physical therapy faculty are not conversant with educational theories and probably do not, unfortunately, use these frameworks to guide or support their growth as educators. As a group they were most familiar with the work of Dewey; however, their beliefs were perhaps more closely aligned with professional theorists such as Reynolds.

In general, physical therapy faculty do not have a robust familiarity with preeminent educational theorists. The findings related to this question are useful in many ways. For example, they can be used by faculty to better understand themselves and their pedagogical practice. Many faculty enter into academia and into ISL without an educational theoretical frame. They enter academia for a variety of reasons, but often they do not have formal education about teaching and /or educational theory. Both ISL and non-ISL faculty may find that their teaching practice improves with an increased awareness of educational theory and the direct influence that that improved knowledge and understanding can have both in and out of the classroom. As for faculty involvement in ISL, it may be entered into because it is believed to be a good or popular idea rather than an idea which is supported by a specific awareness of relevant theoretical frames.

It is also possible that there is limited coherent, underlying theory of physical therapy education. Perhaps the educational practices of faculty are driven by accreditation standards and graduation expectations rather than wellunderstood educational theory. It seems likely that the field - and faculty in the field - have evolved by borrowing heavily from educational theory without being aware of it. A shift to a more obvious and spoken awareness and understanding of educational theory and related literature would only improve physical therapy faculty teaching by providing rationale and evidence for teaching pedagogy. Again, in terms of a common understood language, familiarity with educational theory is beneficial and can help to shape and optimize practice and the discussion of practice. A common understanding of educational theory would provide terminology that enables physical therapy educators to discuss educational and classroom issues at a higher and more comprehensive level. Faculty could in turn utilize educational theory and language to discuss professional development and promotion and tenure issues more adequately.

\section{Comparing Y-ISL and N-ISL Faculty TST and TFT}

When exploring the teaching style types and theoretical frame types of the Y-ISL and N-ISL groups, there were some interesting findings. Both groups were similar in terms of teaching style types. However, interesting differences were found when exploring TFT. Both groups had similar rank orderings for TFT. For both Y-ISL and N-ISL groups, professional theorists were the most common, followed by progressive theorists, and finally critical pedagogues. This seems to coincide with the focus of allied health profession education, which intends to produce professionals who have certain competencies, entry-level attributes, and skills. Professional theorists value teaching and learning opportunities that promote the learning of skills and attributes necessary for the work place. They want their work to help produce competent practitioners in their field and are guided by professional criteria and expectations.

The data show that ISL faculty are more likely than N-ISL faculty to come from a professional theory frame. This suggests that faculty may use ISL as a way for students to practice their clinical skills and attributes in a real world setting where a significant amount of problem solving and critical thinking is required. Perhaps these faculty feel that ISL experiences will prepare their graduates to practice more competently upon graduation. Y-ISL faculty may also have given more thought than N-ISL to the theoretical underpinnings of their teaching.

Additionally, the data also show that subjects' familiarity with key theorists differed: the Y-ISL group was significantly more familiar with both Freire and Reynolds than the N-ISL. Familiarity with Dewey was not significantly different between groups.

\section{Research Question \#3}

The logistic regression was used to attempt to create a model of the typical theoretical frames and teaching styles of faculty doing ISL which provides an answer to Research Question 3: What is the relationship between teaching style and theoretical frame and participation in ISL? 
In the micro-analysis of the multiple regression results, the weight of each of the independent factors in the equation was assessed by looking at the beta weights. This illustrates which of the independent variables share the most variance with the dependent variable. This analysis helped to answer the question: How much does each of the independent variables matter or contribute? Membership in the critical TFT group was identified as statistically significant. This is important because ISL faculty may have a critical pedagogy frame that is best expressed through ISL. It is possible that no other outlet for that frame exist in their everyday teaching since issues are not often addressed in a typical physical therapy classroom.

Macro-analysis of the data answers the question How well does the regression equation determine the dependent variable? or How well do the TFT, TST, and demographic factors predict participation in ISL? Ultimately, logistic regression analysis allows a predictive model to be developed to represent factors that are related to faculty participation in ISL projects. Logistic regression macro-analysis indicates that no strong predictive model can be developed with the data from this study. At this time, using these variables, it is not possible to create a model.

There are three possible explanations for this. First, it could be that the sample was not large enough or robust enough to detect a model (Type II error). In the future it may be possible to create a predictive model by obtaining a larger overall sample with more balance in the number of Y-ISL and N-ISL subjects. Second, it is possible that the groups differ, but on variables not identified in this study. The possibility that there are other more important factors to be explored is intriguing. Such factors might include: past travel experience, comfort with travel, family upbringing (service, travel, etc), previous service activities, immediate personal factors such as family responsibilities, financial factors (does faculty member incur any of the cost of ISL), or religious affiliation. Finally, there, in fact, may be no differences between ISL faculty and others. In the future - with further examination, a larger sample, and identification of additional/different factors - it is possible that a predictive model for faculty ISL participation could be developed.

\section{Value of Study for Institutions of Higher Education}

This study holds value for institutions of higher education in three ways. First, the literature indicates that higher education institutions are investing resources in the development of ISL programs. Because of that, it is important to gain an understanding of faculty involvement in ISL. These data provide a unique perspective to support faculty participation in ISL. In the past, research has only provided a superficial glimpse of faculty and service-learning. Aside from the time and energy impacts of SL on faculty, very little is known. A more in-depth and meaningful consideration of faculty SL and ISL involvement is critical and has yet to be carried out.

Second, higher education institutions need to be able to support teaching and program development with theory and evidence of positive outcomes. Exploration of outcomes should not be limited to student outcomes but should also include faculty-related outcomes. As the review of the literature demonstrates, a substantial body of work related to student learning and behavioral outcomes exists. There is, however, a major void when it comes to faculty outcomes for both SL and ISL. This study begins to pave the way for exploration of faculty-related outcomes for SL and ISL. Third, universities could use the information related to TST and TFT as they consider ISL program and related faculty development. Leaders could undertake program development and faculty development to support and include all faculty - no matter what the demographics, TST, or TFT - to participate.

The importance of understanding and considering teaching styles and relevant theoretical frames is vital to advancing teaching and optimizing student outcomes. Since many faculty may not be very aware of the basis of why they teach the way they do, it would be helpful to be able to connect to some long-standing theoretical support. A better understanding of pedagogical theory might be helpful in the development of faculty who are receiving less than optimal teaching evaluations and want to improve their skills. Further, the teaching style literature and theoretical frame information could be used by program administrators in the development of orientation and mentor programs for young/new faculty members.

\section{Value of Study for the Field of Physical Therapy}

This study has relevance for the profession of physical therapy in two ways. First, the APTA has stated that it is dedicated to looking at global issues in a more directed and cohesive way and developing clinicians who are prepared to practice in a more global environment. The APTA will benefit from data that improve the understanding of what is happening in physical therapy education as a means to that end. The field's vision of becoming more global in its work and collaborative efforts will be strengthened by studies such as this which provide data about what is occurring in physical therapist education and teaching. Additionally, CAPTE might use these data to clarify and provide interpretive guidelines for their accreditation criteria. For instance, physical therapy educational programs may be Using ISL programs to demonstrate compliance with CAPTE standards related to professional behaviors that are often difficult to address in the classroom. When these statements are made, CAPTE could consider at a more aggregated or global level how ISL is being used across the country to meet certain criteria. CAPTE could then develop interpretive guidelines or statements that would provide all physical therapy education programs with information about how to meet CAPTE criteria in better or more dynamic and successful ways. Although CAPTE standards attempt to set a high bar for programs, the bar can still be raised higher. More enlightened, forward- thinking, and globally-focused standards will advance the profession in a direction of true service to our local communities and the world. The integration of 
more explicitly service-oriented student and program outcomes will only benefit the profession and those that we serve. There is no reason that the obviously progressive leanings of ISL PT faculty can't inform, influence, and enhance professional practice standards and the associated accrediting agencies. This would shift the emphasis from "merely" professional standards to a more progressivist and criticalist perspective, thereby enhancing the profession itself and developing a more integrated vision of health and wellness for everyone.

Shifts like these in education, accreditation, and practice would move physical therapists into a role of being stronger advocates for people who are presently under-served. The profession could gain respect and influence and become a more active and dynamic presence in advocating for progress and justice in the global community of health practitioners.

Second, the above benefits along with the prevalence of ISL programs and the data to support their use may be valuable for marketing the field of physical therapy in a broader way that may appeal to prospective physical therapists and to the public.

\section{Value of Study for Physical Therapy Educational Programs}

Physical therapy educational programs may find this study useful in a number of ways. First, consideration of faculty's teaching styles and theoretical frames could inform and enhance faculty development. Educational theory could be tied to teaching approaches, getting all PT educators to be more thoughtful about their teaching and student interactions. An improved understating of TST and TFT may help to bridge the gap for the majority of faculty who have not been formally trained or educated in educational pedagogy prior to finding themselves teaching a classroom full of students. Exploration of student learning styles has been a part of many programs for many years. In the past, however, this has been a one-way street and the data have been used only for the students' sake. Perhaps the student learning style data could be considered by faculty and integrated into how they teach. This may result in adjustment of teaching style in order to optimize student learning. A better understanding of teaching styles and theoretical frameworks will help faculty to better understand their strengths and weaknesses as they relate to teaching and - ultimately - to student evaluations and relationships. It could allow them to better implement strategies that they are comfortable with or to develop new strategies that would better facilitate student learning outcomes. This sort of understanding might allow program directors and faculty to explore how teaching style and theoretical frames influence faculty assignment and performance assessment.

Second, many programs have missions and /or teaching philosophies that would be supported by the theoretical frames presented in this paper, and many are adding ISL opportunities for students. Understanding those frames, and their relationship to ISL efforts by program directors and faculty, is critical to carrying out education in creative and dynamic ways. Theoretical frames could provide an integral link between practice and programmatic missions and philosophies.

Third, knowledge of various theoretical frames can help support the ideas of those faculty who want to explore controversial topics and issues that challenge the status quo. Theory gives legitimacy to - and a framework for - the discussions of topics like diversity, equity, poverty, disenfranchisement, privilege, and social justice. These topics have always been meant for discussion in higher education but are often only included tangentially in physical therapy education. ISL and related theoretical frames provide a potential platform for their discussion and inclusion in the curriculum.

Finally, and perhaps most importantly, the data begin to provide a way for programs to consider looking at the teaching styles and / or theoretical frames of faculty and connect them to the desired student learning outcomes of an SL or ISL course (e.g., social activism, moral development, cultural competence, clinical skills, or some combination of these). For instance, a desired learning outcome for an ISL experience might be improved ability to apply classroom concepts in a real world situation with limited resources. Perhaps there is a faculty teaching style or theoretical frame type that facilitates the achievement of that sort of outcome better than another. Evidence in support of programs that result in positive learning outcomes is critical. Academic programs are becoming more expensive, and educational value is scrutinized by students, their parents, accreditors, and other stakeholders. A typical physical therapy curriculum is very intense and made up almost exclusively of required courses, which leaves little leeway for the addition of electives or activities that do not address accreditation criteria or result in necessary student outcomes. This study's findings may be useful in prompting program directors and faculty to look more closely at which teaching styles and / or theoretical frames are most effective and dynamic in achieving desired outcomes in both ISL and nonISL situations.

\section{Value of Study for Individual Faculty}

For individual faculty members the results of this study are important in two ways. First, considering the potential relevance of teaching style and its relationship with teaching and learning, this information can inform faculty practice, particularly for individual faculty who care about the quality of what they do, student outcomes, and student satisfaction. An understanding of teaching styles encourages instructors to think about who they are as teachers 
and to reflect on the outcomes they want to achieve with students. A better understanding of teaching style allows instructional strategies to become grounded in a conceptual base of knowledge about teaching and learning. Second, many faculty enter academia without a background in education, hence familiarity with educational theory is often limited. Improved understanding of educational theory and individual affiliation to those theories can help faculty grow professionally and to more effectively utilize instructional strategies that begin to serve broader philosophical, theoretical, and conceptual goals.

\section{Study Limitations}

When interpreting the results of this study readers should be mindful of several limitations. First, the sample was not random, and therefore potential bias is introduced. The sample chosen may not be representative of all faculty in physical therapy programs. Because of the way the sample was sought, it may be biased toward faculty who are active in the Education Section of the APTA or have a particular interest in global issues. The sample might have been more representative if all faculty members of physical therapy educational programs had been contacted directly.

Secondly, data were collected with two tools that did not have supporting reliability and validity data. One of these tools, the Grasha and Reichmann scale of Teaching Styles, was developed with consideration of psychometric properties, but these data were not available, even from the tool's authors. The second tool without supporting reliability and validity data was the researcher-developed Theoretical Frame section of the Faculty Survey.

A third element that should be considered when interpreting the results of this study was the difference between established teaching style clusters and the teaching style clusters of these subjects. These data did not match the literature, and un-validated clusters were identified in the data and used in the subsequent data analysis.

Finally, a larger sample size would support more extensive regression analyses. This sample may not have been large enough to support the number of variables entered into the logistic regression resulting in limited statistical power. Additionally, the unequal number of subjects in the Y-ISL and N-ISL groups may have contributed to potential Type II errors.

\section{Suggestions for Future Research}

This study just scratches the surface of an area where little information exists, and there is much more to be learned about both physical therapy faculty and the use of ISL in physical therapy curriculum. It lays a foundation for future research in several areas related to physical therapy faculty, TST, TFT, and the use of ISL as pedagogy in physical therapy education.

First, the faculty survey should be further developed and refined for broader use by researchers and other interested parties. Item and factor analyses should be carried out to establish reliability and validity data for the Faculty Survey tool. Some questions could be adjusted to yield more informative responses. For instance, the questions related to familiarity with key theorists could be asked in a way that elicits information about general familiarity as well as specific knowledge of theorists.

Second, there is very little descriptive information, teaching style information, or theoretical frame information available about physical therapy faculty, and even less is known about ISL faculty. As physical therapy programs develop faculty and add ISL components, more data will be necessary to support those efforts. There are stronger theoretical and ethical underpinnings to ISL that have yet to be explored. For instance, ISL faculty tend to self-identify as professional theorists but are really progressives at heart. They also have a strong commitment to ISL but only vague notions about why it is so important (beyond the beliefs that it gives hands-on practice in challenging clinical situations and that "it's a good idea"). Further, they seem to have an intuitive understanding of progressive "constructivism" and an emerging commitment to social justice as it pertains to health care. Additional scholarly and conceptual investigation could better clarify the significance, purpose, and desired outcomes of ISL experiences in the profession.

Future qualitative and quantitative research might include studies that look in more depth at ISL faculty, investigate physical therapy student ISL outcomes, explore how ISL can be used to address CAPTE standards associated with either clinical or professional student outcomes, and examine cost-benefit analyses of ISL programs. Answers to the following questions would add significantly to the ISL literature:

- How does ISL serve the profession in terms of the APTA strategic plan and Vision 20/20

- Why are PT programs adding ISL components?

- Are ISL programs cost effective? In what ways? 
- What are the benefits of ISL participation for students?

- What CAPTE standards can be met through ISL programs?

- What faculty are best suited to lead ISL programs?

- Does teaching style and/or theoretical frame matter for assignment of faculty to ISL? Does one group or another have better student outcomes in general or in relation to ISL?

- How many faculty have a formal background/credentials in education?

- Are faculty who have a background in education or familiarity with educational theorists "better" teachers than those who don't?

- Are certain teaching styles more effective in physical therapy education or in certain subject areas?

- Does the number of years of clinical practice prior to going into academia correlate with TST or TFT?

- Does faculty teaching style and/or theoretical frame correlate with primary area of interest and corresponding teaching?

- Do physical therapy students have teaching style preferences? If so what do they prefer and/or learn the most from?

\section{Summary}

The findings from this study are useful in addressing each of the research questions. The data provide valuable information that can add to what is known about ISL on many levels. This study holds true for institutions of higher education, the field of physical therapy in general, physical therapy educational programs both with and without ISL programs, and individual faculty.

\section{Final Comments}

Even with its limitations, this study is salient because it builds on what is presently known about SL in general and ISL specifically and advances the literature in the previously unstudied area of physical therapy faculty. This study is important and unique because it provides information that deepens a very shallow pool of knowledge in the area of ISL. Indeed, in physical therapy, no study has explored faculty variables in any realm of ISL. The findings from this study will be of interest to many stakeholders, including the physical therapy profession, physical therapy educational programs, program faculty, students, and educational accreditation agencies. Additionally, it can serve as an inspiration for the field of physical therapy to open a dialogue about faculty practice and teaching, for programs to continue with and develop ISL efforts, and for faculty to reflect on their teaching practices. 
Section 1: Participant Demographics

1. Age:

2. Gender:

3. Entry Level PT Degree?

Bachelors

Masters

MPT

DPT

4. Years as a PT?

5. Faculty Position?

Lecturer

Clinical Assistant Professor

Associate Professor

Other Professor

6. Total years teaching in physical therapy programs?

Section 2: Teaching Style Items - The Teaching Style Survey (Grasha \& Reichmann-Hruska, Copyright 1996)

Respond to each of the items below in terms of how you teach. If you teach some courses differently than others, respond to items in terms of the course that is your favorite course to teach. Try to answer as honestly and as objectively as you can. Resist the temptation to respond as you believe you should or ought to think or behave, or in terms of what you believe is the expected or proper thing to do.

Respond to questions below by using the following rating scale:

1 = strongly disagree $\mid \mathbf{2}=$ moderately disagree $\mid 3=$ undecided $\mid$

4 = moderately agree $\mid 5$ = strongly agree

1. Facts, concepts, and principles are the most important things that students should acquire.

2. I set high standards for students in this class.

3. What I say and do models appropriate ways for students to think about issues in the content.

4. My teaching goals and methods address a variety of student learning styles.

5. Students typically work on course projects alone with little supervision from me.

6. Sharing my knowledge and expertise with students is very important to me.

7. I give students negative feedback when their performance is unsatisfactory.

8. Activities in this class encourage students to develop their own ideas about content issues.

9. I spend time consulting with students on how to improve their work on individual and/or group projects.

10. Activities in this class encourage students to develop their own ideas about content issues.

11. What I have to say about a topic is important for students to acquire a broader perspective on the issues in that area.

12. Students would describe my standards and expectations as somewhat strict and rigid.

13. I typically show students how and what to do in order to master course content.

14. Small group discussions are employed to help students develop their ability to think critically. 
15. Students design one or more self-directed learning experience.

16. I want students to leave this course well prepared for further work in this area.

17. It is my responsibility to define what students must learn and how they should learn it.

18. Examples from my personal experiences often are used to illustrate points about the material.

19. I guide students' work on course projects by asking questions, exploring options, and suggesting alternative ways to do things.

20. Developing the ability of students to think and work independently is an important goal.

21. Lecturing is a significant part of how I teach each of the class sessions.

22. I provide very clear guidelines for how I want tasks completed in this course.

23. I often show students how they can use various principles and concepts.

24. Course activities encourage students to take initiative and responsibility for their learning.

25. Students take responsibility for teaching part of the class sessions.

26. My expertise is typically used to resolve disagreements about content issues.

27. This course has very specific goals and objectives that I want to accomplish.

28. Students receive frequent verbal and/or written comments on their performance.

29. I solicit student advice about how and what to teach in this course.

30. Students set their own pace for completing independent and/or group projects.

31. Students might describe me as a "storehouse of knowledge" who dispenses the fact, principles, and concepts they need.

32. My expectations for what I want students to do in this class are clearly defined in the syllabus.

33. Eventually, many students begin to think like me about course content.

34. Students can make choices among activities in order to complete course requirements.

35. My approach to teaching is similar to a manager of a work group who delegates tasks and responsibilities to subordinates.

36. There is more material in this course than I have time available to cover it.

37. My standards and expectations help students develop the discipline the need to learn.

38. Students might describe me as a "coach" who works closely with someone to correct problems in how they think and behave.

39. I give students a lot of personal support and encouragement to do well in this course.

40. I assume the role of a resource person who is available to students whenever they need help. 
Section 3: Theoretical Frame Items

From your perspective as a physical therapy educator, please read each of the following statements and indicate your level of dis/agreement on a scale of 1-10.

1. Higher education is the continuation of a developmental and progressive process.

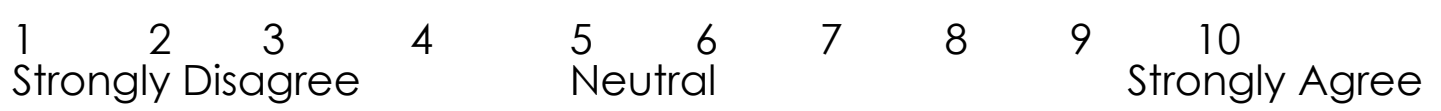

2. Higher education is an opportunity to raise consciousness about, criticize, and

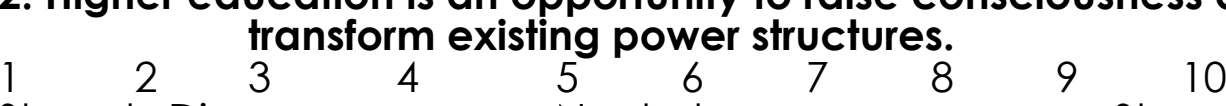

Strongly Disagree Neutral Strongly Agree

3. Higher education is an opportunity to develop skills that will be useful in the workplace.

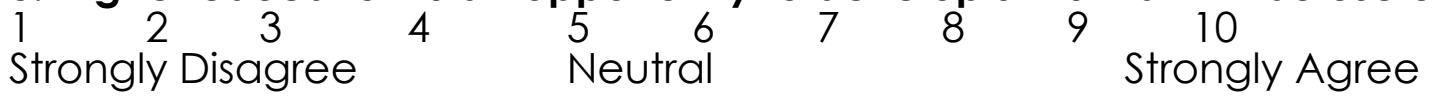

4. Students in higher education are problem-solvers who will develop increased understanding and control over their

$\begin{array}{llllllll}\text { own learning. } & & & & & \\ 1 & 4 & 5 & 6 & 7 & 8 & 9 & 10 \\ \text { Strongly Disagree } & & \text { Neutral } & & & & \text { Strongly Agree }\end{array}$

5. Students in higher education are critical thinkers who will develop the ability to transform environments and achieve social justice.

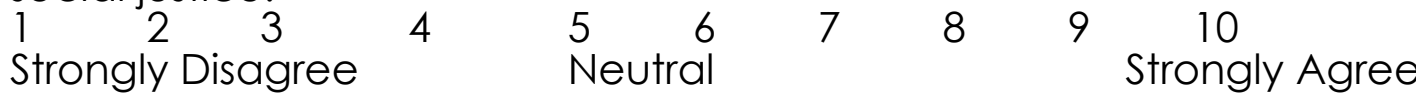

6. Students in higher education are learning the art and science of their professional fields.

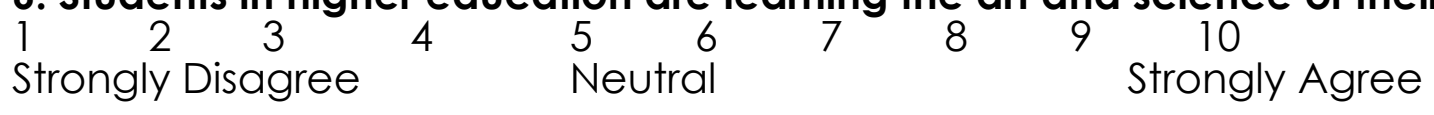

7. The ultimate goal of higher education is to empower students to become autonomous, democratic citizens.

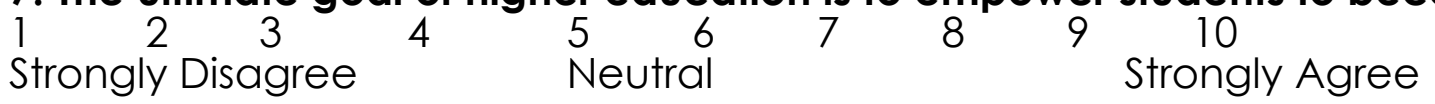

8. The ultimate goal of higher education is to empower students to become activists who criticize accepted power structures and ideas.

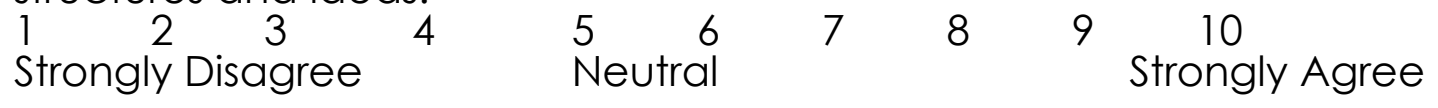

9. The ultimate goal of higher education is to empower students to become excellent practitioners.
123 Strongly Disagree
$\begin{array}{ll}5 & 6 \\ \text { Neutral }\end{array}$
$9 \quad 10$
Strongly Agree

10. College students learn best through experiences that are meaningful and simulate real-life situations.
$\begin{array}{ll}1 & 2 \\ \text { Strongly Disagree }\end{array}$
$\begin{array}{lll}4 & 5 & 6 \\ & \text { Neutral }\end{array}$
78
$9 \quad 10$
Strongly Agree

11. College students learn best through problem-posing that raises social consciousness.
$\begin{array}{ll}1 & 2 \\ \text { Strongly Disagree }\end{array}$
4
$5 \quad 6$
$7 \quad 8 \quad 9 \quad 10$

12. College students learn best through experiences that have specific goals and expected outcomes.
1
Strongly Disagree
$5 \quad 6$
78
910
10
Strongly Agree

13. When teaching I often use current / real world events to which students can relate.
$1.2 \quad 3$
Strongly Disagree
$5 \quad 6$
9 10
Strongly Agree

14. When teaching I often use socially unjust situations as examples.
$\begin{array}{ll}1 & 2 \\ \text { Strongly Disagree }\end{array}$
$5 \quad 6$
89
10
Strongly Agree

15. When teaching I often use case study examples.
$\begin{array}{ll}11 & 2 \\ \text { Strongly Disagree }\end{array}$
$5 \quad 6$
$78^{9} \quad 10$
Strongly Agree

16. When I teach I try to draw on the diverse backgrounds, capabilities and individual talents of students.
1
1
Strongly Disagree
56
$7 \quad 89$
10
Strongly Agree

17. When I teach I try to draw on the diverse relationships to and perceptions of power structures.
1
1
Strongly Disagree
$5 \quad 6$
78
9 10
Strongly Agree 
18. When I teach I try to draw on the diverse knowledge and thinking skills of students.

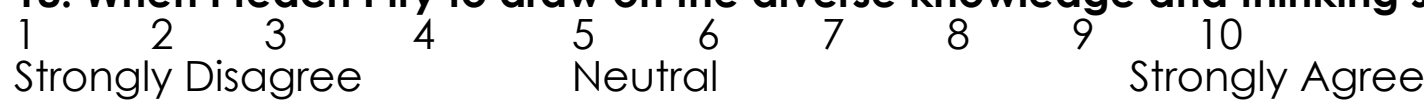

19. My teaching practices would best be described as democratic.

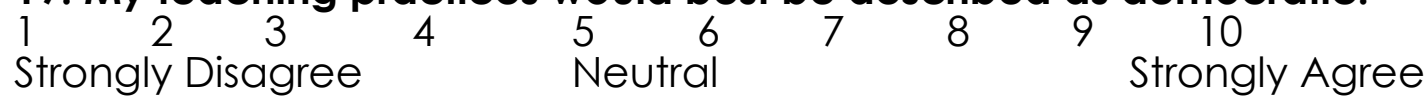

20. My teaching practices would best be described as socialist.

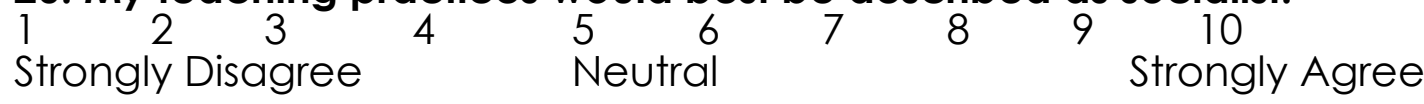

21. My teaching practices would best be described as authoritative.

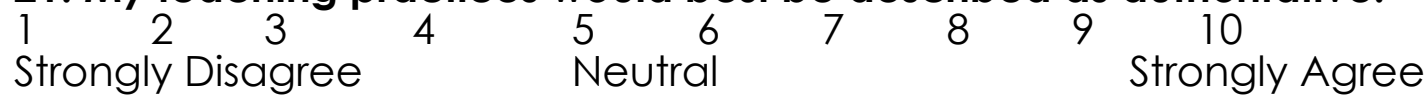

22. In order to enhance learning I encourage assignments that encourage action followed by reflection, then action based on the reflection.

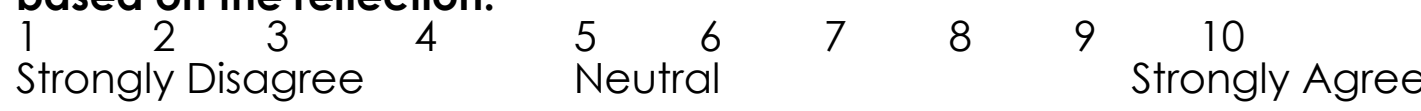

23. In order to enhance learning I encourage assignments that encourage action aimed at personal and social transformation.

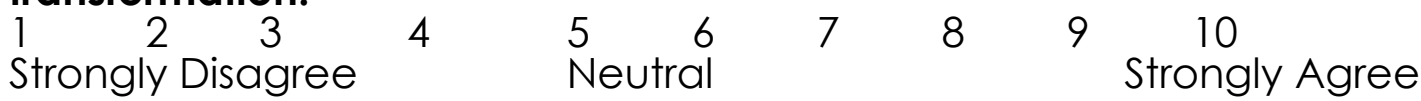

24. In order to enhance learning I encourage assignments that encourage action.

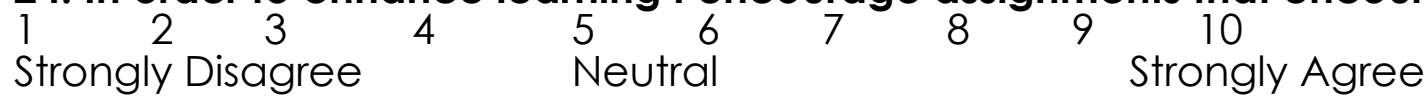

25. I plan the content of the courses I teach based on a balance of what past students have expressed as being important and what I think is important.

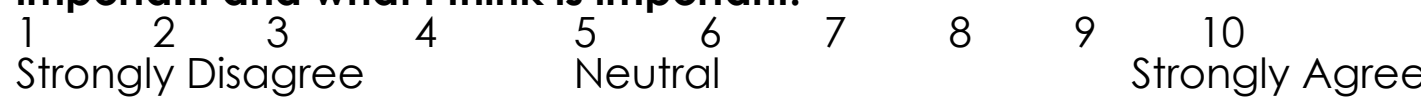

26. I plan the content of the courses I teach based on the imperative to work for social justice.

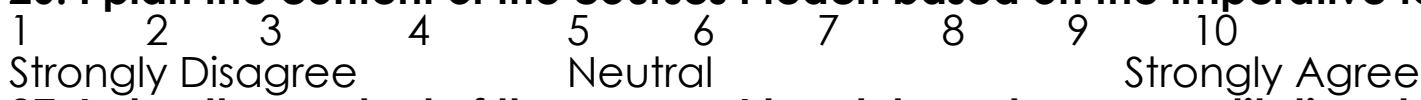

27. I plan the content of the courses I teach based on accreditation standards and guidelines.

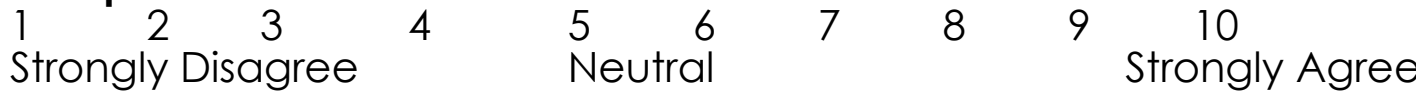

28. I think that the current state of higher education is too prescriptive and unaccommodating of individual interests.

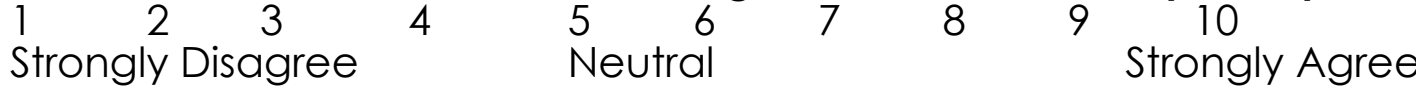

29. I think that the current state of higher education is too supportive and uncritical of the status quo.

$\begin{array}{lcccccccc}1 & 2 & 3 & 4 & 5 & 6 & 7 & 8 & 9 \\ \text { Strongly Disagree } & & \text { Neutral } & & & & 10 \\ \text { Strongly Agree }\end{array}$

30. I think that the current state of higher education is too controlled by outside stakeholders (professional organizations, accrediting bodies, etc.).

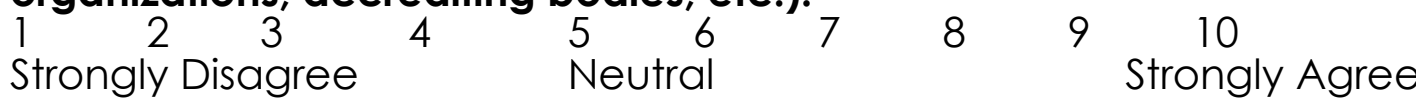

31. On a scale of 1-10 how familiar are you with the writings of John Dewey?

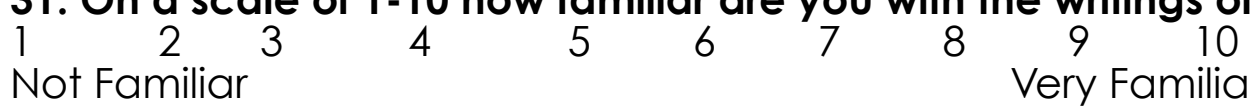

32. On a scale of 1-10 how familiar are you with the writings of Paulo Freire?

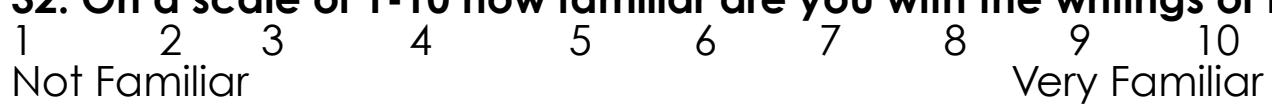

33. On a scale of 1-10 how familiar are you with the writings of Pamela Reynolds?

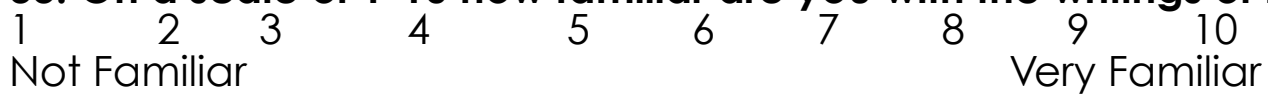




\section{Section 4: ISL Participation Items}

1. Have you ever participated in an international service learning experience with students? Yes

If No, you have completed this survey.

If Yes, please answer the following questions.

2. How many trips have you taken with students?

3. Please list the location, year, and size of the group taken for each trip.

\begin{tabular}{|l|l|l|}
\hline Location & Year & $\begin{array}{l}\text { Approximate \# of } \\
\text { students }\end{array}$ \\
\hline & & . \\
\hline
\end{tabular}

4. When you do an international service-learning trip:

Do you have multiple class meetings prior to the trip to discuss issues other than travel logistics?
If Yes, do those meetings include:

A structured meeting schedule

Discussion of assigned readings

Goal setting

Discussion of cross cultural issues

Other, please specify

5. When you do an international service-learning trip:

Is there a formal opportunity for students to reflect? Yes No

If Yes, please check all modes of reflection utilized.

Journaling

Post experience written reflection

Post experience oral reflection

Other, please specify

6. Do you speak a foreign language that you use during ISL experiences?

Yes No

\begin{tabular}{|l|l|}
\hline $\begin{array}{l}\text { Which } \\
\text { language(s)? }\end{array}$ & \begin{tabular}{l} 
Level of fluency? \\
\hline
\end{tabular} \\
\hline & $\begin{array}{l}\text { Poor 1----2----3----4----5----6----7----8----9----10 } \\
\text { Fluent } \\
\text { Poor 1----2----3-----4----5----6----7----8-----9----10 } \\
\text { Fluent }\end{array}$ \\
\hline
\end{tabular}


Appendix B: Teaching Style Type Weighting

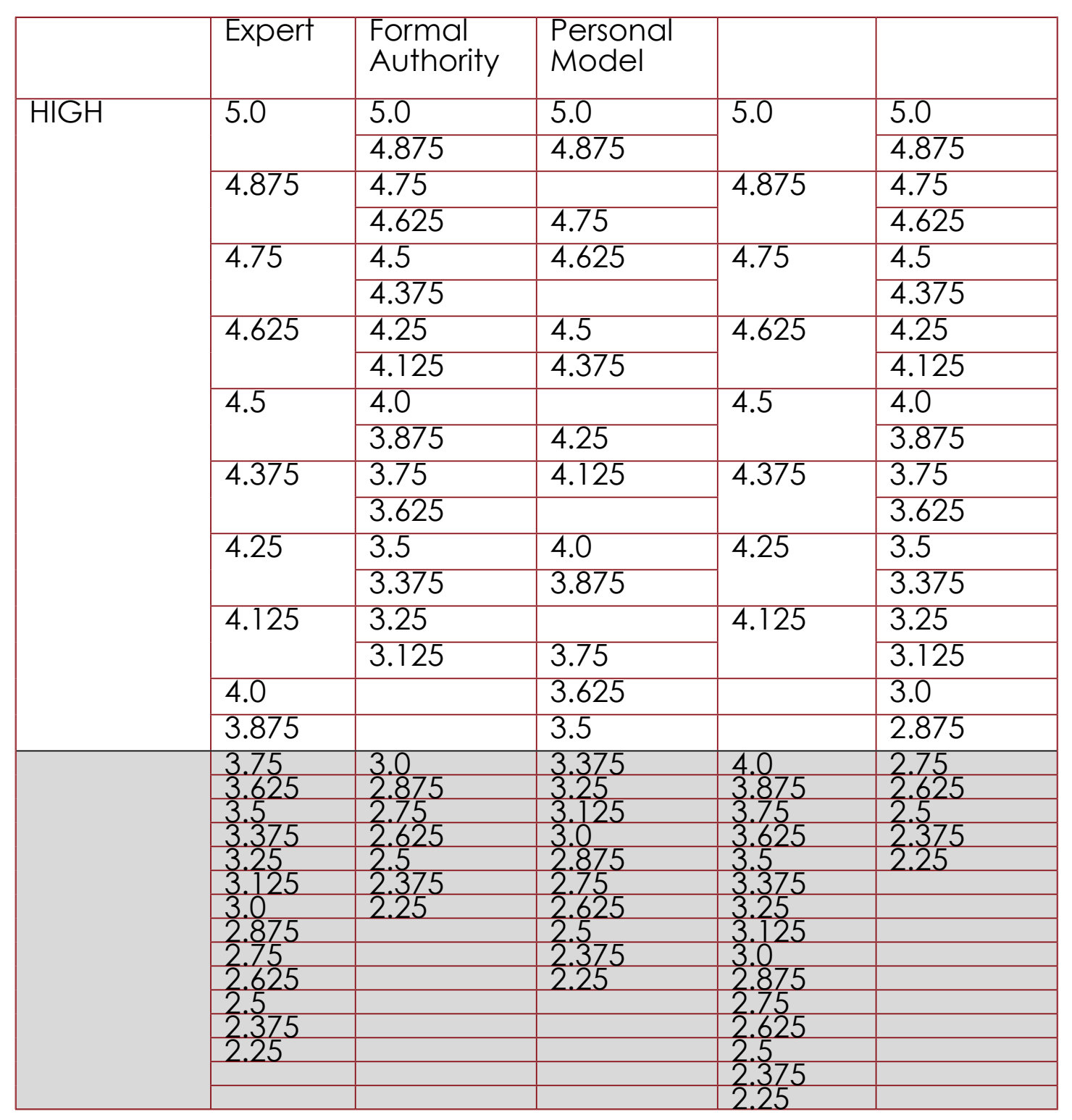




\section{Cluster 1: Expert / Formal Authority}

This cluster is a relatively rigid cluster type dominated by the Expert style where the teacher is a transmitter of information and possesses knowledge that (s)he feels students need. The teacher strives to maintain his/her status by displaying and transmitting detailed knowledge. These teachers challenge students to enhance their competence and ensure student preparation. The secondary type; Formal Authority sets standards and defines acceptable ways of doing things. This instructor gain status among students through their role and knowledge. These teachers are concerned with providing feedback, establishing goals, expectations, and rules of conduct for students. They are also concerned with correct, acceptable, and standard ways of doing things.

\section{Cluster 2: Personal Model / Formal Authority / Delegator}

Faculty who fall into this cluster are most identified with the Personal Model type, yet they have some of the more rigid characteristics of the Formal Authority type. They teach by illustration and direct example and believe in teaching by personal example and establish a prototype for how to think and behave. These instructors encourage students to observe and emulate their approach. The teacher acts as a guide who oversees and directs. These teachers use a very hands-on approach. The Formal Authority side sets high standards and expectations and gains status with students through a focus on clear expectations and acceptable ways of doing things. In addition, faculty who fall into this cluster have a component of the Delegator type which allows them to focus on developing students' ability to function autonomously. They encourage students to work independently or as part of a team. These teachers make themselves available as a resource person and encourage students to perceive themselves as independent learners.

\section{Cluster 3: Formal Authority / Delegator}

Faculty who fall into this cluster are most identified with the Formal Authority type, yet they have some of the characteristic of a Delegator. They teach by setting high standards and expectations and gains status with students through a focus on clear expectations and acceptable ways of doing things. This instructor possesses status among students because of knowledge and role. These teachers are concerned with providing positive and negative feedback, establishing learning goals, expectations, and rules of conduct for students. They are also concerned with correct, acceptable, and standard ways of doing things. The advantage of this style is a focus on clear expectations and acceptable ways of doing things. The delegator side allows them to focus on developing students' ability to function autonomously. They encourage students to work independently or as part of a team. These teachers make themselves available as a resource person and encourage students to perceive themselves as independent learners.

\section{Cluster 4: Formal Authority / Facilitator / Delegator}

In this cluster Formal Authority is the primary style, however it is offset by Facilitator and Delegator characteristics. This teacher sets standards and defines acceptable ways of doing things. This instructor possesses status among students because of knowledge and role. These teachers are concerned with providing positive and negative feedback, establishing learning goals, expectations, and rules of conduct for students. They are also concerned with correct, acceptable, and standard ways of doing things. The Facilitator characteristics add components of guiding and directing by asking questions, exploring options, and suggesting alternatives. Emphasis is given to consultation and the personal nature of teacher-student interactions. The facilitator's overall goal for students is that they develop the capacity for independent action and responsibility with support and encouragement. Delegator characteristics also influence this cluster type and they include focusing on student autonomy. Students are encouraged to work independently with additional instruction and resources at the request of students.

\section{Cluster 5: Delegator / Facilitator}

In this cluster Delegator becomes the primary style. This teacher tends to focus on developing students' ability to function autonomously by using independent and group assignments. These teachers act as consultants who are available to students as needed. The Facilitator characteristics of this cluster include guidance and supports and directs by asking questions, exploring options, and suggesting alternatives that will enhance learning. Emphasis is placed on the personal nature of teacher-student interactions and students are encouraged to develop criteria to make informed choices. 


\section{REFERENCES}

Abes, E. S., Jackson, G., \& Jones, S. R. (2002). Factors that motivate and deter faculty use of service-learning. Michigan Journal of Community Service Learning. 9(1), 5-17.

Ash, S. L., Clayton, P. H., \& Atkinson, M. P. (2005). Integrating reflection and assessment to capture and improve student learning. Michigan Journal of Community Service Learning. 11 (2), 49-60.

American Physical Therapy Association. Accessed 10/4/10 at www.apta.org

Banerjee, M., \& Hausafus, C. O. (2007). Faculty use of service-learning: Perceptions, motivations, and impediments for the human sciences. Michigan Journal of Community Service Learning. 14(1), 32-45.

Beling, J. (2004). Impact of service learning on physical therapist students' knowledge of attitudes toward older adults and on their critical thinking ability. Journal of Physical Therapy Education. 18(1), 13-21.

Bogdan, R. C., \& Biklen, S. K. (2003). Qualitative Research for Education: An Introduction to Theories and Methods (4th ed.). New York, NY: Pearson Education Group.

Bradley, L. R. (1997). Evaluating Service-Learning Toward a New Paradigm. In A. S. Waterman (Ed.), Service-learning: Applications from the research (pp. 151-172). Mahwah, NJ: Lawrence Erlbaum Associates.

Braskamp, L. A. (2008). Developing global citizens. Journal of College and Character. 10(1), 1-7.

Bringle, R. G., \& Hatcher, J. A. (1995). A service-learning curriculum for faculty. Michigan Journal of Community Service Learning. 2, 33-42.

Bringle, R. G., \& Hatcher, J. A. (1996). Implementing service learning in higher education. Journal of Higher Education. $67(2), 221-239$.

Bringle, R. G., \& Hatcher, J. A. (2000). Meaningful measurement of theory-based service-learning outcomes: Making the case with quantitative research. Michigan Journal of Community Service Learning. Special Issue: Strategic Directions for Service-Learning Research, 68-75.

Brody, S. M., \& Wright, S. C. (2004). Expanding the self through service-learning. Michigan Journal of Community Service Learning. $11(1), 14-24$.

Brown, A. (1987). Metacognition, executive control, self-regulation, and other more mysterious mechanisms. In Weinert and Klew (Eds.). Metacognition, motivation, and understanding (pp. 65-117). LEA.

Chisholm, L. A. (2003). Partnerships for International Service-Learning. In Barbra J. \& associates (Eds.), Building partnerships for service-learning. (pp. 259-288). San Francisco, CA: Jossey-Bass.

Cooks, L., \& Scharrer, E. (2006). Assessing learning in community service learning: A social approach. Michigan Journal of Community Service Learning. 13(2), 44-55.

CORD ( (2007). Teaching styles inventory. Accessed 12/18/08 at http://www.texascollaborative.org/TSI.htm

Craft, R. J. (2002). International service learning. In M. E. Kenny, L. A. K. Simon, K. Kiley- Brabeck, \& R. M. Lerner (Eds.), Learning to serve: Promoting civil society through service learning (pp. 297-313). Boston, MA: Kluwer Academic Publishers.

Daynes, G., \& Longo, N. V. (2004). Jane Addams and the origins of service-learning practice in the United States. Michigan Journal of Community Service Learning. $11(1), 5-13$.

Deans, T. (1999). Service-learning in two keys: Paulo Freire's critical pedagogy in relation to John Dewey's pragmatism. Michigan Journal of Community Service Learning. 6, 15-29.

Dewey, J. (1916). Democracy and Education. An Introduction to the Philosophy of Education (1966 edn.). New York, NY: Free Press.

Dewey, J. (1933). How We Think. A Restatement of the Relation of Reflective Thinking to the Educative Process (Revised edn.). Boston: D. C. Heath.

Dewey, J. (1938). Experience and Education. New York, NY: Collier Books. 
Dockter, M. K. (2004). An international service-learning experience for physical therapy students: Its meaning and effect on civic engagement and leadership skills. Dissertation. Grand Forks, ND: University of North Dakota.

Donaldson, M. (1978). The shape of minds to come. In Children's Minds (pp. 127-135). New York, NY: W. W. Norton.

Driscoll, A. (2000). Studying faculty and service-learning: Directions for inquiry and development. Michigan Journal of Community Service Learning. Special Issue: Strategic Directions for Service-Learning Research, 35-41.

Driscoll, A., Holland, B., Gelmon, S., \& Kerrigan, S. (1996). An assessment model for service-learning: Comprehensive case studies of impact on faculty, students, community, and institution. Michigan Journal of Community Service Learning, 3, 66-71.

Ewell, P. T. (1985). Some implications for practice. In P. T. Ewell (Ed.), Assessing educational outcomes (pp. 111-119). San Francisco: Jossey-Bass.

Eyler, J., \& Giles, D. (1997). The Importance of Program Quality in Service-Learning. In A. S. Waterman, (Ed.) Servicelearning: Applications from the research (pp. 57-76). Mahwah, NJ: Lawrence Erlbaum Associates.

Eyler, J., Giles, D. E., \& Braxton, J. (1997). The impact of service-learning on college students. Michigan Journal of Community Service Learning, 4, 5-15.

Fenzel, L. M., \& Peyrot, M. (2005). Comparing college community participation and future service behaviors and attitudes. Michigan Journal of Community Service Learning, 12(1), 23-31.

Fosnot, C. T. (1996). Constructivism: Theory, Perspectives, and Practice. New York, NY: Teachers College Press.

Freire, P. (1993). Pedagogy of the oppressed, $20^{\text {th }}$ Anniversary Ed. New York: Continuum.

Ganley, K. J., \& Mueller, K. (2006). Clinically relevant outcomes of immersion in a community service based experience for physical therapy students. Pediatric Physical Therapy, 18(1), 90-101.

Gelmon, S. B. (2000). Challenges in assessing service learning. Michigan Journal of Community Service Learning. Special Issue: Strategic Directions for Service-Learning Research, 84-90.

Gelmon, S. B. (2000). How do we know that our service work makes a difference? Assessment strategies for servicelearning and civic engagement. Metropolitan Universities: An International Forum. 11 (2), 28-39.

Gelmon, S., Holland, B., Driscoll, A., Spring, A., \& Kerrigan, S. (2002). Assessing service-learning and civic engagement: Principles and techniques. Michigan Journal of Community Service Learning. 8(2), 75-78.

Giles, D. E., \& Eyler, J. (1994). The theoretical roots of service-learning in John Dewey: Toward a theory of servicelearning. Michigan Journal of Community Service Learning. 1(1), 77-85.

Giroux, H. (2010). Lessons from Paulo Freire. Chronical of Higher Education. October 17. Retrieved December 12, 2010 from http://chronicle.com/article/Lessons-From-Paulo-Freire/124910/.

Goulet, C., \& Owen-Smith, P. (2005). Cognitive-affective learning in physical therapy education: From implicit to explicit. Journal of Physical Therapy Education, 19(3), 67-72.

Grasha, A. F. (1994). A matter of style: The teacher as expert, formal authority, personal model, facilitator, and delegator. College Teaching, 42(4), 142-49.

Grasha, A. F. (1994). A special section discovering your best teaching style. College Teaching, 42 (4), 122-124.

Grasha, A. F. (1996). Teaching with style; A practical guide to enhancing learning by understanding teaching and learning styles. Pittsburgh, PA: Alliance Publishers.

Grasha, A. F. \& Reichmann-Hruska, S. (1996). Teaching style survey. Cincinnati, OH: University of Cincinnati.

Grusky, S. (2000). International service learning. American Behavioral Scientist, 43(5), 858-867.

Hammond, C. (1994). Integrating service and academic study: Faculty motivation and satisfaction in Michigan higher education. Michigan Journal of Community Service Learning, 1(1), 21-28. 
Harlow, L. L. (2005). The essence of multivariate thinking. Mahwah, NJ: Erlbaum.

Hartman, D., \& Rola, G. (2000). Going global with service learning. Metropolitan Universities: An International Forum, $11(1), 15-23$.

Harwood, A. M., Ochs, L., Currier, D., Duke, S., Hammond, J., Moulds, L., Stout, K., \& Werder, C. (2005). Communities for growth: Cultivating and sustaining service-learning teaching and scholarship in a faculty fellows program. Michigan Journal of Community Service Learning, 12(1), 41-51.

Hatcher, J. A. (1997). The moral dimensions of John Dewey's philosophy: Implications for undergraduate education. Michigan Journal of Community Service Learning. 4, 22-29.

Hatcher, J. A., \& Bringle, R. G. (1997). Reflection: Bridging the gap between service and learning. College Teaching, $45(4), 153-158$.

Hatcher, J. A., Bringle, R. G., \& Muthiah, R. (2004). Designing effective reflection: What matters to service-learning? Michigan Journal of Community Service Learning, $11(1), 38-46$.

Hesser, G. (1995). Faculty assessment of student learning: Outcomes attributed to service-learning and evidence of changes in faculty attitudes about experiential education. Michigan Journal of Community Service Learning, 2 , 33-42.

Hofer, B. K., \& Pintrich, P. R. (1997). The development of epistemological theories: Beliefs about knowledge and knowing and their relation to learning. Review of Education Research. 67(1), 88-140.

Hoppes, S., Bender, D., \& Degrace, B.W. (2005). A service learning is a perfect fit for occupational and physical therapy education. Journal of Allied Health. 34(1), 47-50.

Kahne, J., \& Westheimer, J. (1996). In service of what? The politics of service learning. Phi Delta Kappan. 77, 593-599.

Kahne, J., Westheimer, J. \& Rogers, B. (2000). Service learning and citizenship: Directions for research. Michigan Journal of Community Service Learning. Fall, $42-51$.

Keith, N. Z. (2005). Community service learning in the face of globalization: Rethinking theory and practice. Michigan Journal of Community Service Learning, 11 (2), 5-24.

Kendrick, J. R. (1996). Outcomes of service-learning in an introduction to sociology course. Michigan Journal of Community Service Learning, 3, 72-81.

Kiely, R. (2004). A chameleon with a complex: Searching for transformation in international service-learning. Michigan Journal of Community Service Learning, 10(2), 5-20.

Kiely, R., \& Nielson, D. (2003). International service learning: The importance of partnerships. Community College Journal, 39-41.

King, J. T. (2004). Service-Learning as a site for critical pedagogy: A case of collaboration, caring, and defamiliarization across borders. Journal of Experiential Education, 26(3), 121-137.

King, P. M., \& Kitchener, K. S. (1994). Developing Reflective Judgment. San Francisco, CA: Jossey-Bass Publishers.

Kohlberg, L., \& Mayer, R. (1972). Development as the aim of education. Harvard Educational Review. 42(4), 449-496.

Kolb, D. A. (1984). Experiential learning: Experiences as a source of learning and development. Englewood Cliffs, NJ: Prentice Hall.

Koplan, J. P., Bond, T. C., Merson, M. H., Reddy, K. S., Rodriguez, M. H., Sewankambo, N. K., \& Wasserheit, J. N. (2009). Towards a common definition of global health. The Lancet, 373(9679), 1993-5.

Levine, M. A. (1994). Seven steps to getting faculty involved in service-learning: How a traditional faculty member came to teach a course on "Voluntarism, Community, and Citizenship." Michigan Journal of Community Service Learning. $1(1), 110-114$.

Lewis, A., \& Smith, D. (1993). Defining higher order thinking. Theory Into Practice. 32 (3), 131-137. 
Lincoln, Y. (1992). Curriculum studies and the tradition of inquiry: The humanistic tradition. In P. Jackson (Ed.), Handbook of Research on Curriculum (pp. 79-97). New York, N. Y.: Macmillan.

Lowery, D., May, D. L., Duchane, K. A., Coulter-Kern, R., De' Bryant, Morris, P. V., Pomery, J. G., \& Bellner, M. (2006). A logic model of service-learning: Tensions and issues for further consideration. Michigan Journal of Community Service Learning. 12(2), 47-60.

Magnuson, S. J., \& Palincsar, A. S. (1995). The learning environment as a sight of science education reform. Theory Into Practice. 34 (1), 43-51.

McKay, V. C., \& Rozee, P. D. (2004). Characteristics of faculty who adopt community service learning pedagogy. Michigan Journal of Community Service Learning, 10(2), 21-33.

Miller, J. (1994). Linking traditional and service-learning courses: Outcome evaluations utilizing two pedagological distinct models. Michigan Journal of Community Service Learning, 1(1), 29-36.

Miller, J. (1997). The impact of service-learning experiences on students' sense of power. Michigan Journal of Community Service Learning, 4, 16-21.

Monte, C. F., \& Sollod, R. N. (2003). Beneath the mask: An introduction to theories of personality (7 $7^{\text {th }}$ ed.). John Wiley and Sons, Inc.: Hoboken, NJ.

Myers-Lipton, S. J. (1996). Effect of service-learning on college students' attitudes toward international understanding. Journal of College Student Development, 37(6), 659-668.

O'Meara, K., \& Niehaus, E. (2009). Service-learning is... How faculty explain their practice. Michigan Journal of Community Service Learning, 16(1), 17-32.

Palomba, C. A., \& Banta, T. W. (1999). Assessment essentials: Planning, implementing, and improving assessment in higher education. San Francisco: Jossey-Bass.

Parker, B., \& Dautoff, D. A. (2007). Service-learning and study abroad: Synergistic learning opportunities. Michigan Journal of Community Service Learning, 13(2), 40-53.

Patterson, A. S. (2000). It's a small world: Incorporating service learning into international relations courses. Political Science and Politics, 33(4) 817-22.

Pechak, C., \& Thompson, M. (2009). International service-learning and other international volunteer service opportunities in physical therapist education programs in the USA and Canada. Journal of Physical Therapy Education, 23(1), 71-79.

Perry, W. (1970). Forms of Intellectual and Ethical Development in the College Years: A Scheme. NY, NY: Holt, Rinehart, and Winston.

Piaget, J. (1964). Cognitive development in children: Development and learning. Journal of Research in Science Teaching. 40, s8-S18.

Porter M., \& Monard, K. (2001) Ayni in the global village: Building relationships of reciprocity through international service-learning. Michigan Journal of Community Service Learning, 8(1), 5-17.

Portney, L. G., \& Watkins, M. P. (2000). Foundations of clinical research: Applications to practice (2 ${ }^{\text {nd }}$ Ed.). Upper Saddle River, NJ: Prentice Hall Health.

Pribbenow, D. A. (2005). The impact of service-learning pedagogy on faculty teaching and learning. Michigan Journal of Community Service Learning, 11 (2), 25-38.

Protsman, L., \& Carlson, M. (2008). Graphic organizers can facilitate selection of statistical tests: Part 2 - correlation and regression analysis. Journal of Physical Therapy Education, 22 (2), 36-41.

Pyle, K. R. (1981). International cross-cultural service/learning: Impact on student development. Journal of College Student Personnel, $22(6), 509-514$.

Reicherter, F. A., \& Manual Williams, B. (2005). Service learning in physical therapy: Enhancing healthy lifestyles of older African American adults in Washington, DC. Creative College Teaching Journal, 2(1):65-77.

Reynolds, P. J. (2005). How service-learning experiences benefit physical therapist students' professional development: 
a grounded theory study. Journal of Physical Therapy Education, 19(1), 41-51.

Riner, M. E., \& Becklenberg, A. (2001). Partnering with a sister city organization for an international service-learning experience. Journal of Transcultural Nursing, 12 (3), 234-240.

Roberts, B. (2000). Good guidance on the ground: Mentoring international service learning programs. Metropolitan Universities: An International Forum, 11 (1), 45-52.

Seifer, S. D. (1998). Service-learning: Community-campus partnerships for health professions education. Academic Medicine, 73(3):273-277.

Silver, H. S., Hanson, J. R., Strong, R. W., \& Schwartz, P. B. (1996). Teaching styles and strategies. Woodbridge, NJ; Thoughtful Education Press.

Serow, R. C. (1997). Research and Evaluation on Service-Learning: A Case for Holistic Assessment. In A. S. Waterman (Ed.), Service-learning: Applications from the research (pp. 13-24). Mahwah, NJ: Lawrence Erlbaum Associates.

Shor, I. (1992). Empowering Education. University of Chicago Press, Chicago.

Silcox, H. C., \& Leek, T. E. (1997). International service learning: Its time has come. Phi Delta Kappan, 78(8), 615-18.

Silcox, H. C., \& Sweeney, S. (1993). A people-to-people environmental program in Russia: Experiential service learning in Novgorod, Russia. Journal of Experiential Education, 16(1) 25-27.

Simon, D. (Ed.) (2006). Fifty key thinkers on development. New York, NY: Routledge publishing.

Sotnik, P., \& Jezewski, M. A. (2005). Culture and Disability. In J. H. Stone (Ed.) Culture and disability: Providing culturally competent services. (pp. 15-36) Thousand Oaks, CA: Sage Publications.

Stachowski, L. L., \& Visconti, V. A. (1998). Service learning in overseas nations: U.S. student teachers give, grow, and gain outside the classroom. Journal of Teacher Education, 49(3), 212-219.

Tishman, S., Jay, E., \& Perkins, D. N. (1993). Teaching thinking dispositions: From transmission to enculturation. Theory Into Practice. $32(3), 147-153$.

The 4MAT® Teaching Style Inventory (TSI). Accessed 12/18/08 at http://www.aboutlearning.com/index.php/learning-assessments/ teaching-styles-inventory

Underbakke, M., Borg, J. M., \& Peterson, D. (1993). Researching and developing the knowledge base for teaching higher order thinking. Theory Into Practice. 32(3), 147-153.

Village, D., Clouten, N., Millar, A. L., Geigle, A., Okafor, N., Simuel, D., \& Uzarraga, A. (2004). Comparison of the use of service learning, volunteer, and pro bono activities in physical therapy curricula. Journal of Physical Therapy Education, 18(1), 22-28.

Vygotsky, L. (1968). Mind in society: The development of higher psychological processes. Cambridge, MA: Harvard University Press.

Weiss, N. A. (2005). Introductory statistics (7 $7^{\text {th }}$ ed.). NY, NY: Pearson Addison.

Williams, D., \& Eiserman, W. D. (1997). Expanding the dialogue: Service learning in Costa Rica and Indonesia. Michigan Journal of Community Service Learning, 4, 90-97.

Zhang, L. F. (2004). Thinking styles: University students' preferred teaching styles and their conceptions of effective teachers. Journal of Psychology, 138(3), 233-252. 
A Normative Model of Physical Therapist Professional Education: Version 2004. Alexandria, VA: American Physical Therapy Association; 2004.

Abes, E. S., Jackson, G., \& Jones, S. R. (2002). Factors that motivate and deter faculty use of service-learning. Michigan Journal of Community Service Learning. 9(1), 5-17.

Ambady, N., Koo, J., Rosenthal, R., \& Winograd, C. (2002). Physical therapists' nonverbal communication predicts geriatric patients' health outcomes. Psychology and Aging, 17(3), 443-452.

American Physical Therapy Association. Accessed 10/4/10 at www.apta.org

Andrews, D., Nonnecke, B., \& Preece, J. (2003). Electronic survey methodology. A case study in reaching hard to involve Internet Users. International Journal of Human-Computer Interaction, 16(2), 185-210.

Ash, S. L., Clayton, P. H., \& Atkinson, M. P. (2005). Integrating reflection and assessment to capture and improve student learning. Michigan Journal of Community Service Learning. 11 (2), 49-60.

Banerjee, M., \& Hausafus, C. O. (2007). Faculty use of service-learning: Perceptions, motivations, and impediments for the human sciences. Michigan Journal of Community Service Learning. 14(1), 32-45.

Banta, T. W., Lund, J. P., Black, K. E., \& Oblander, F. W. (1996). Assessment in practice: Putting principles to work on college campuses. San Francisco, CA: Jossey-Bass.

Barbara K., Kaye, B. K., \& Johnson, T. J. (1999). Research methodology: Taming the cyber frontier: Techniques for improving online surveys. Social Science Computer Review, 17(3), 323-337.

Beling, J. (2004). Impact of service learning on physical therapist students' knowledge of attitudes toward older adults and on their critical thinking ability. Journal of Physical Therapy Education. 18(1), 13-21.

Billig, S. H., \& Waterman, A. S. (2003). Studying service-learning: Innovations in education research methodology. Mahwah, NJ: Erlbaum.

Black, S. (1996). Peak performance. Executive Educator. 17 (3), 30-34.

Bogdan, R. C., \& Biklen, S. K. (2003). Qualitative Research for Education: An Introduction to Theories and Methods (4th ed.). New York, NY: Pearson Education Group.

Bradley, L. R. (1997). Evaluating Service-Learning Toward a New Paradigm. In A. S. Waterman (Ed.), Service-learning: Applications from the research (pp. 151-172). Mahwah, NJ: Lawrence Erlbaum Associates.

Braskamp, L. A. (2008). Developing global citizens. Journal of College and Character. 10(1), 1-7.

Bringle, R. G., \& Hatcher, J. A. (1995). A service-learning curriculum for faculty. Michigan Journal of Community Service Learning. 2, 33-42.

Bringle, R. G., \& Hatcher, J. A. (1996). Implementing service learning in higher education. Journal of Higher Education. $67(2), 221-239$

Bringle, R. G., \& Hatcher, J. A. (2000). Meaningful measurement of theory-based service-learning outcomes: Making the case with quantitative research. Michigan Journal of Community Service Learning. Special Issue: Strategic Directions for Service-Learning Research, 68-75.

Brody, S. M., \& Wright, S. C. (2004). Expanding the self through service-learning. Michigan Journal of Community Service Learning. $11(1), 14-24$.

Brown, A. (1987). Metacognition, executive control, self-regulation, and other more mysterious mechanisms. In Weinert and Klew (Eds.). Metacognition, motivation, and understanding (pp. 65-117). LEA.

Chisholm, L. A. (1997). International service-learning. Black Collegian, 27 (2), 149-152.

Chisholm, L. A. (2003). Partnerships for International Service-Learning. In Barbra J. \& associates (Eds.), Building partnerships for service-learning. (pp. 259-288). San Francisco, CA: Jossey-Bass. 
Code of Ethics. American Physical Therapy Association. Available at http://www.apta.org/governance/HOD/policies/ HoDPolicies/Section I/ETHICS/HOD 06001223.

Commission on Accreditation for Physical Therapy Education. Evaluative Criteria for Accreditation of Education Programs for the Preparation of Physical Therapists. Alexandria, VA: American Physical Therapy Association; 2006.

Cooks, L., \& Scharrer, E. (2006). Assessing learning in community service learning: A social approach. Michigan Journal of Community Service Learning. 13(2), 44-55.

CORD ( (2007). Teaching styles inventory. Accessed 12/18/08 at http://www.texascollaborative.org/TSI.htm

Cozby, P. C. (1989). Methods in behavioral research, $4^{\text {th }}$ ed., Mountain View, CA: Mayfield Publishing Company.

Craft, R. J. (2002). International service learning. In M. E. Kenny, L. A. K. Simon, K. Kiley- Brabeck, \& R. M. Lerner (Eds.), Learning to serve: Promoting civil society through service learning (pp. 297-313). Boston, MA: Kluwer Academic Publishers.

Currier, D. P. (1990). Elements of research in physical therapy. Baltimor, MD: Williams and Wilkins.

Davis, R. N. (1999).Web-based administration of a personality questionnaire: Comparison with traditional methods. Behavioral Research Methods Instrumentation and Computation, 31 (4), 572-577.

Daynes, G., \& Longo, N. V. (2004). Jane Addams and the origins of service-learning practice in the United States. Michigan Journal of Community Service Learning. $11(1), 5-13$.

Deans, T. (1999). Service-learning in two keys: Paulo Freire's critical pedagogy in relation to John Dewey's pragmatism. Michigan Journal of Community Service Learning. 6, 15-29.

Dewey, J. (1916). Democracy and Education. An Introduction to the Philosophy of Education (1966 edn.). New York, NY: Free Press.

Dewey, J. (1933). How We Think. A Restatement of the Relation of Reflective Thinking to the Educative Process (Revised edn.). Boston: D. C. Heath.

Dewey, J. (1938). Experience and Education. New York, NY: Collier Books.

Dockter, M. K. (2004). An international service-learning experience for physical therapy students: Its meaning and effect on civic engagement and leadership skills. Dissertation. Grand Forks, ND: University of North Dakota.

Donaldson, M. (1978). The shape of minds to come. In Children's Minds (pp. 127-135). New York, NY: W. W. Norton.

Driscoll, A. (2000). Studying faculty and service-learning: Directions for inquiry and development. Michigan Journal of Community Service Learning. Special Issue: Strategic Directions for Service-Learning Research, 35-41.

Driscoll, A., Holland, B., Gelmon, S., \& Kerrigan, S. (1996). An assessment model for service-learning: Comprehensive case studies of impact on faculty, students, community, and institution. Michigan Journal of Community Service Learning, 3, 66-71.

Ewell, P. T. (1985). Some implications for practice. In P. T. Ewell (Ed.), Assessing educational outcomes (pp. 111-119). San Francisco: Jossey-Bass.

Eyler, J., \& Giles, D. (1997). The Importance of Program Quality in Service-Learning. In A. S. Waterman, (Ed.) Servicelearning: Applications from the research (pp. 57-76). Mahwah, NJ: Lawrence Erlbaum Associates.

Eyler, J., Giles, D. E., \& Braxton, J. (1997). The impact of service-learning on college students. Michigan Journal of Community Service Learning, 4, 5-15.

Fenzel, L. M., \& Peyrot, M. (2005). Comparing college community participation and future service behaviors and attitudes. Michigan Journal of Community Service Learning, 12(1), 23-31.

Fosnot, C. T. (1996). Constructivism: Theory, Perspectives, and Practice. New York, NY: Teachers College Press.

Freire, P. (1993). Pedagogy of the oppressed, $20^{\text {th }}$ Anniversary Ed. New York: Continuum. 
Ganley, K. J., \& Mueller, K. (2006). Clinically relevant outcomes of immersion in a community service based experience for physical therapy students. Pediatric Physical Therapy, 18(1), 90-101.

Gelmon, S. B. (2000). Challenges in assessing service learning. Michigan Journal of Community Service Learning. Special Issue: Strategic Directions for Service-Learning Research, 84-90.

Gelmon, S. B. (2000). How do we know that our service work makes a difference? Assessment strategies for servicelearning and civic engagement. Metropolitan Universities: An International Forum. 11 (2), 28-39.

Gelmon, S., Holland, B., Driscoll, A., Spring, A., \& Kerrigan, S. (2002). Assessing service-learning and civic engagement: Principles and techniques. Michigan Journal of Community Service Learning. 8(2), 75-78.

Giroux, H. (2010). Lessons from Paulo Freire. Chronical of Higher Education. October 17. Retrieved December 12, 2010 from http://chronicle.com/article/Lessons-From-Paulo-Freire/124910/.

Giles, D. E., \& Eyler, J. (1994). The theoretical roots of service-learning in John Dewey: Toward a theory of service learning. Michigan Journal of Community Service Learning. 1(1), 77-85.

Goulet, C., \& Owen-Smith, P. (2005). Cognitive-affective learning in physical therapy education: From implicit to explicit. Journal of Physical Therapy Education, 19(3), 67-72.

Grasha, A. F. (1994). A matter of style: The teacher as expert, formal authority, personal model, facilitator, and delegator. College Teaching, 42(4), 142-49.

Grasha, A. F. (1994). A special section discovering your best teaching style. College Teaching, 42(4), 122-124.

Grasha, A. F. (1996). Teaching with style; A practical guide to enhancing learning by understanding teaching and learning styles. Pittsburgh, PA: Alliance Publishers.

Grasha, A. F., \& Reichmann-Hruska, S. (1996). Teaching style survey. Cincinnati, OH: University of Cincinnati.

Gravetter, F. J. \& Wallnau, L. B. (2005). Essentials of statistics for the behavioral sciences, $5^{\text {th }}$ edition. Belmont, CA: Wadsworth / Thomson Learning.

Grusky, S. (2000). International service learning. American Behavioral Scientist, 43(5), 858-867.

Guide to Physical Therapist Practice: $2^{\text {nd }}$ Edition (2001). Alexandria, VA: American Physical Therapy Association; 2001.

Hammond, C. (1994). Integrating service and academic study: Faculty motivation and satisfaction in Michigan higher education. Michigan Journal of Community Service Learning, 1(1), 21-28.

Harlow, L. L. (2005). The essence of multivariate thinking. Mahwah, NJ: Erlbaum.

Hartman, D., \& Rola, G. (2000). Going global with service learning. Metropolitan Universities: An International Forum, $11(1), 15-23$.

Harwood, A. M., Ochs, L., Currier, D., Duke, S., Hammond, J., Moulds, L., Stout, K., \& Werder, C. (2005). Communities for growth: Cultivating and sustaining service-learning teaching and scholarship in a faculty fellows program. Michigan Journal of Community Service Learning, 12(1), 41-51.

Hatcher, J. A. (1997). The moral dimensions of John Dewey's philosophy: Implications for undergraduate education. Michigan Journal of Community Service Learning. 4, 22-29.

Hatcher, J. A., \& Bringle, R. G. (1997). Reflection: Bridging the gap between service and learning. College Teaching, $45(4), 153-158$.

Hatcher, J. A., Bringle, R. G., \& Muthiah, R. (2004). Designing effective reflection: What matters to service-learning? Michigan Journal of Community Service Learning, $11(1), 38-46$.

Hesser, G. (1995). Faculty assessment of student learning: Outcomes attributed to service-learning and evidence of changes in faculty attitudes about experiential education. Michigan Journal of Community Service Learning, 2, 33-42.

Hofer, B. K., \& Pintrich, P. R. (1997). The development of epistemological theories: Beliefs about knowledge and knowing 
and their relation to learning. Review of Education Research. 67(1), 88-140.

Hoppes, S., Bender, D., \& Degrace, B.W. (2005). A service learning is a perfect fit for occupational and physical therapy education. Journal of Allied Health. 34(1), 47-50.

Jeager, R. M. (1997). Complimentary methods for research in education (2 ${ }^{\text {nd }}$ Ed.). Washington, DC: American Educational Research Association.

Jensen, G. M., Gwyer, J., Shepard, K. F., \& Hack, L. M. (2000). Expert practice in physical therapy. Physical Therapy. $80(1), 28-42$.

Jette, D. U., \& Portney, L. G. (2003). Construct validation of a model for professional behavior in physical therapy students. Physical Therapy, 83(5), 432-443.

Kahne, J., \& Westheimer, J. (1996). In service of what? The politics of service learning. Phi Delta Kappan. 77, 593-599.

Kahne, J., Westheimer, J., \& Rogers, B. (2000). Service learning and citizenship: Directions for research. Michigan Journal of Community Service Learning. Fall, $42-51$.

Kaplan, A. (1963). The conduct of inquiry: Methodology for behavioral science. New York, NY: Harper \& Row.

Keith, N. Z. (2005). Community service learning in the face of globalization: Rethinking theory and practice. Michigan Journal of Community Service Learning, 11 (2), 5-24.

Kendrick, J. R. (1996). Outcomes of service-learning in an introduction to sociology course. Michigan Journal of Community Service Learning, 3, 72-81.

Kiely, R. (2004). A chameleon with a complex: Searching for transformation in international service-learning. Michigan Journal of Community Service Learning, 10(2), 5-20.

Kiely, R., \& Nielson, D. (2003). International service learning: The importance of partnerships. Community College Journal, 39-41.

Kiesler, S., \& Sproull, L. S. (1986). Response effects in the electronic survey. Public Opinion Quarterly, 50(3), 402-413.

King, J. T. (2004). Service-Learning as a site for critical pedagogy: A case of collaboration, caring, and defamiliarization across borders. Journal of Experiential Education, 26(3), 121-137.

King, P. M., \& Kitchener, K. S. (1994). Developing Reflective Judgment. San Francisco, CA: Jossey-Bass Publishers.

Kohlberg, L., \& Mayer, R. (1972). Development as the aim of education. Harvard Educational Review. 42(4), 449-496.

Kolb, D. A. (1984). Experiential learning: Experiences as a source of learning and development. Englewood Cliffs, NJ: Prentice Hall.

Koplan, J. P., Bond, T. C., Merson, M. H., Reddy, K. S., Rodriguez, M. H., Sewankambo, N. K., \& Wasserheit, J. N. (2009). Towards a common definition of global health. The Lancet, 373(9679), 1993-5.

Kuhn, D. (1999). A developmental model of critical thinking. Educational Researcher. 28 (2), 16-26.

Kumagai, A. K., \& Lipson, M. L. (2009). Beyond cultural competence: Critical consciousness, social justice, and multicultural education. Academic Medicine, 84(6), 782-788.

Lazar, J., \& Preece, J. (1999). Designing and implementing web-based surveys. The Journal of Computer Information Systems. Xxxix(4), 63-67.

Lenert, L., \& Schozen, S. (2002).The internet as a research tool: Worth the price of admission? Annals of Behavioral Medicine, 24(4), 251-256.

Levine, M. A. (1994). Seven steps to getting faculty involved in service-learning: How a traditional faculty member came to teach a course on "Voluntarism, Community, and Citizenship." Michigan Journal of Community Service Learning. 1(1), 110-114.

Lewis, A., \& Smith, D. (1993). Defining higher order thinking. Theory Into Practice. 32 (3), 131-137. 
Lincoln, Y. (1992). Curriculum studies and the tradition of inquiry: The humanistic tradition. In P. Jackson (Ed.), Handbook of Research on Curriculum (pp. 79-97). New York, N. Y.: Macmillan.

Lopopolo, R. B., Schafer, D. S., \& Nosse, L. J. (2004). Leadership, administration, management, and professionalism (LAMP) in physical therapy: A Delphi study. Physical Therapy, 84(2), 137-150.

Lowery, D., May, D. L., Duchane, K. A., Coulter-Kern, R., De' Bryant, Morris, P. V., Pomery, J. G., \& Bellner, M. (2006). A logic model of service-learning: Tensions and issues for further consideration. Michigan Journal of Community Service Learning. 12(2), 47-60.

Magnuson, S. J., \& Palincsar, A. S. (1995). The learning environment as a sight of science education reform. Theory Into Practice. 34 (1), 43-51.

Masin, H. L. (2002). Education in the affective domain: A method / model for teaching professional behaviors in the classroom and during advisory sessions. Journal of Physical Therapy Education, 16(1), 41-54.

McKay, V. C., \& Rozee, P. D. (2004). Characteristics of faculty who adopt community service learning pedagogy. Michigan Journal of Community Service Learning, 10(2), 21-33.

Mehta, R., \& Sivadas, E. (1995). Comparing response rates and response content in mail versus electronic surveys. Journal of Market Research Society, 37(4), 429-440.

Miller, J. (1994). Linking traditional and service-learning courses: Outcome evaluations utilizing two pedagological distinct models. Michigan Journal of Community Service Learning, 1 (1), 29-36.

Miller, J. (1997). The impact of service-learning experiences on students' sense of power. Michigan Journal of Community Service Learning, 4, 16-21.

Monte, C.F., \& Sollod, R. N. (2003). Beneath the mask: An introduction to theories of personality (7th ed.). John Wiley and Sons, Inc.: Hoboken, NJ.

Myers-Lipton, S. J. (1996). Effect of service-learning on college students' attitudes toward international understanding. Journal of College Student Development, 37(6), 659-668.

Nosse, L. J., \& Sagiv, L. (2005). Theory-based study of the basic values of 565 physical therapists. Physical Therapy, 85(9), 834-849.

O'Meara, K., \& Niehaus, E. (2009). Service-learning is... How faculty explain their practice. Michigan Journal of Community Service Learning, 16(1), 17-32.

Palomba, C. A., \& Banta, T. W. (1999). Assessment essentials: Planning, implementing, and improving assessment in higher education. San Francisco: Jossey-Bass.

Parker, B., \& Dautoff, D. A. (2007). Service-learning and study abroad: Synergistic learning opportunities. Michigan Journal of Community Service Learning, 13(2), 40-53.

Patterson, A. S. (2000). It's a small world: Incorporating service learning into international relations courses. Political Science and Politics, 33(4) 817-22.

Pealer, L. N., Weiler, R. M., Pigg Jr, R. M., Miller, D., \& Dorman, S. M. (2001).The feasibility of a web-based surveillance system to collect health risk behavior data from college students. Health Education Behavior, 28(5), 547-559.

Pechak, C., \& Thompson, M. (2009). International service-learning and other international volunteer service opportunities in physical therapist education programs in the USA and Canada. Journal of Physical Therapy Education, 23(1), 71-79.

Perry, W. (1970). Forms of Intellectual and Ethical Development in the College Years: A Scheme. NY, NY: Holt, Rinehart, and Winston.

Piaget, J. (1964). Cognitive development in children: Development and learning. Journal of Research in Science Teaching. 40, S8-S18.

Pike, G. (2002). Measurement issues in outcomes assessment. In T. W. Banta (Ed), Building a scholarship of assessment (pp. 131-147). San Francisco, CA: Jossey-Bass.

Porter M., \& Monard, K. (2001) Ayni in the global village: Building relationships of reciprocity through international 
service-learning. Michigan Journal of Community Service Learning, 8(1), 5-17.

Portney, L. G., \& Watkins, M. P. (2000). Foundations of clinical research: Applications to practice (2 ${ }^{\text {nd }}$ Ed.). Upper Saddle River, NJ: Prentice Hall Health.

Pribbenow, D. A. (2005). The impact of service-learning pedagogy on faculty teaching and learning. Michigan Journal of Community Service Learning, 11 (2), 25-38.

Protsman, L., \& Carlson, M. (2008). Graphic organizers can facilitate selection of statistical tests: Part 2 - correlation and regression analysis. Journal of Physical Therapy Education, 22 (2), 36-41.

Pyle, K. R. (1981). International cross-cultural service/learning: Impact on student development. Journal of College Student Personnel, 22(6), 509-514.

Reicherter, F. A., \& Manual Williams, B. (2005). Service learning in physical therapy: enhancing healthy lifestyles of older African American adults in Washington, DC. Creative College Teaching Journal, 2(1):65-77.

Resnik, L., \& Hart, D. L. (2003). Using clinical outcomes to identify expert physical therapists. Physical Therapy, 83(1 1), 990-1002.

Resnik, L., \& Jensen, G. M. (2003). Using clinical outcomes to explore the theory of expert practice in physical therapy. Physical Therapy, 83(12), 1090-1106.

Reynolds, P. J. (2005). How service-learning experiences benefit physical therapist students' professional development: a grounded theory study. Journal of Physical Therapy Education, 19(1), 41-51.

Rhodes, S. D., Bowie, D. A., \& Hergenrather, K. C. (2003). Collecting behavioural data using the world wide web: Considerations for researchers. Journal of Epidemiology and Community Health, 57, 68-73.

Riner, M. E., \& Becklenberg, A. (2001). Partnering with a sister city organization for an international service-learning experience. Journal of Transcultural Nursing, 12 (3), 234-240.

Ritter P., Lorig K., Laurent D., \& Matthews K. (2004). Internet versus mailed questionnaires: A randomized comparison. Journal of Medical Internet Research, 6(3), e29.

Roberts, B. (2000). Good guidance on the ground: Mentoring international service learning programs. Metropolitan Universities: An International Forum, 11 (1), 45-52.

Seifer S. D. (1998). Service-learning: Community-campus partnerships for health professions education. Academic Medicine, 73(3):273-277.

Silver, H. S., Hanson, J. R., Strong, R. W., \& Schwartz, P. B. (1996). Teaching styles and strategies. Woodbridge, NJ; Thoughtful Education Press.

Serow, R. C. (1997). Research and Evaluation on Service-Learning: A Case for Holistic Assessment. In A. S. Waterman (Ed.), Service-learning: Applications from the research (pp. 13-24). Mahwah, NJ: Lawrence Erlbaum Associates.

Shor, I. (1992). Empowering Education. University of Chicago Press, Chicago.

Silcox, H. C., \& Leek, T. E. (1997). International service learning: Its time has come. Phi Delta Kappan, 78(8), 615-18.

Silcox, H. C., \& Sweeney, S. (1993). A people-to-people environmental program in Russia: Experiential service learning in Novgorod, Russia. Journal of Experiential Education, 16(1) 25-27.

Silver, H. F., Hanson, J. R., Strong, R. W., \& Schwartz, P. B. (1996). Teaching styles and strategies (3rd ed.). Woodbridge, NJ: Thoughtful Education Press.

Simon, D. (Ed.) (2006). Fifty key thinkers on development. New York, NY: Routledge publishing.

Stachowski, L. L., \& Visconti, V. A. (1998). Service learning in overseas nations: U.S. student teachers give, grow, and gain outside the classroom. Journal of Teacher Education, 49(3), 212-219.

Sotnik, P., \& Jezewski, M. A. (2005). Culture and Disability. In J. H. Stone (Ed.) Culture and disability: Providing culturally competent services. (pp. 15-36) Thousand Oaks, CA: Sage Publications. 
Standards of Practice and the Criteria. American Physical Therapy Association. Accessed 10/20/10 at http://www. apta.org/governance/HOD/policies/HoDPolicies/Section I/PRACTICE/HOD 06001122.

Stanton, J. M. (1998). An empirical assessment of data collection using the Internet. Personnel Psychology, 51 (3), 709 726.

Tishman, S., Jay, E., \& Perkins, D. N. (1993). Teaching thinking dispositions: From transmission to enculturation. Theory Into Practice. $32(3), 147-153$.

The 4MAT® Teaching Style Inventory (TSI). Accessed 12/18/08 at http://www.aboutlearning.com/index.php/learning-assessments/ teaching-styles-inventory

Underbakke, M., Borg, J. M., \& Peterson, D. (1993). Researching and developing the knowledge base for teaching higher order thinking. Theory Into Practice. 32(3), 147-153.

Vendrely, A. (2005). Critical thinking skills during a physical therapist professional education program. Journal of Physical Therapy Education, 19(1), 55-59.

Village, D., Clouten, N., Millar, A. L., Geigle, A., Okafor, N., Simuel, D., \& Uzarraga, A. (2004). Comparison of the use of service learning, volunteer, and pro bono activities in physical therapy curricula. Journal of Physical Therapy Education, 18(1), 22-28.

Vygotsky, L. (1968). Mind in society: The development of higher psychological processes. Cambridge, MA: Harvard University Press.

Weiss, N. A. (2005). Introductory statistics (7 $7^{\text {th }}$ ed.). NY, NY: Pearson Addison.

Williams, D. D., Hricko, M., \& Howell, S. L. (2006). Online assessment, measurement, and evaluation: Emerging practices. Hershey, PA: Information Science Publishing.

Williams, D., \& Eiserman, W. D. (1997). Expanding the dialogue: Service learning in Costa Rica and Indonesia. Michigan Journal of Community Service Learning, 4, 90-97.

Wolff-Burke, M. (2005). Clinical instructors' descriptions of physical therapist student professional behaviors. Journal of Physical Therapy Education, 19(1), 55-59.

Zhang, L. F. (2004). Thinking styles: University students' preferred teaching styles and their conceptions of effective teachers. Journal of Psychology, 138(3), 233-252. 